Check for updates

Cite this: RSC Adv., 2018, 8, 22023

Received 18th April 2018 Accepted 6th June 2018

DOI: $10.1039 / \mathrm{c} 8 \mathrm{ra03339k}$

rsc.li/rsc-advances

\section{Development of nanofibrillar morphologies in poly(L-lactide)/poly(amide) blends: role of the matrix elasticity and identification of the critical shear rate for the nodular/fibrillar transition $\uparrow$}

\author{
M. Yousfi, (D)* T. Dadouche, D. Chomat, C. Samuel, (D) J. Soulestin, M.-F. Lacrampe \\ and P. Krawczak (D)
}

Bio-based poly(L-lactide)/poly(amide-11) blends (PLA/PA11, 80/20 w/w) and poly(L-lactide)/poly(amide-6) blends (PLA/PA6, 80/20 w/w) are processed by twin-screw extrusion followed by injection-moulding and key rheological parameters controlling their morphologie are investigated. The same work is done using the same PLA modified by a multi-step reactive extrusion route with an epoxy-based chain extender to obtain modified poly(lactide)/poly(amide-11) (PLA-j/PA11 80/20 w/w) blends. The morphologies of the extruded materials and of the injection moulded parts are characterized by SEM and their formation is deeply discussed via rheological investigation to highlight the contribution of viscosity, elasticity and interfacial tension. The existence of a critical shear rate related to the transition from nodular to fibrillar morphology is highlighted and the results are in good agreement with the condition of fibrillation $\mathrm{Ca} / \mathrm{Ca}_{(\text {crit })} \geq 4$. Interestingly, with the exception of PLA/PA6 specimens, all blends obviously display uniform thin-thread fibrillar morphologies after injection-moulding. Compared with pure PLA, a drastic increase of the ductility was observed in the blends exhibiting a fiberlike structure without meanwhile sacrificing the stiffness. This study confirms that, through the appropriate choice of blend components (viscosity and elasticity ratio, flow conditions, interfacial tensions) the in situ fibrillation concept provides access, at a reasonable cost, to new materials with improved thermomechanical performances, without sacrificing weight and ability to be recycled.

\section{Introduction}

Polymer blends are important industrial materials which are, still further, gaining in practical importance and scientific interest since the development of a blend is more economical than the synthesis of new functional polymer, which not only involves high costs but also cannot satisfy industrial demand. ${ }^{1}$ The great majority of useful polymer blends are not miscible, but their physical properties could be optimized by controlling the quality of the dispersion which depends on the melt rheological properties as well as on the mode of deformation of the blend components during compounding and/or processing stages. Compared to conventional composite materials which contain rigid fillers, polymer blends form a multiphase system with a deformable dispersed phase. Due to the complex nature of deformation of the minor phase, polymer blends have the potential of generating a wide range of morphologies during

IMT Lille Douai, Institut Mines-Télecom, Department of Polymer and Composite Technology \& Mechanical Engineering (TPCIM), 941 rue Charles Bourseul, CS 10838, F-59508 Douai, France. E-mail: mohamed.yousfi@imt-lille-douai.fr

$\dagger$ Electronic supplementary information (ESI) available. See DOI: 10.1039/c8ra03339k melt processing. These morphologies can roughly be divided in two classes: co-continuous systems and dispersion-like systems. In the latter, spherical, ellipsoidal, fibrillar or droplet-in-droplet morphologies have been reported in the scientific literature even with same composition. ${ }^{2}$

The morphology created by the blending of immiscible fluids in industrial processes is the product of droplet deformation, breakup and coalescence. Taylor ${ }^{3}$ found that in purely viscous newtonian systems, the deformation and breakup of drops, is governed by two dimensionless parameters: the first one is ratio of the viscosity of the dispersed phase $\left(\eta_{\mathrm{d}}\right)$ to that of the continuous phase $\left(\eta_{\mathrm{m}}\right)$ denoted $k\left(k=\eta_{\mathrm{d}} / \eta_{\mathrm{m}}\right)$, the second one is the Weber (or capillary) number, $\mathrm{Ca}$, which represents the ratio of the viscous stresses imposed on the droplet by the external flow field to the interfacial tension forces that tend to restore the droplet to a spherical shape. The capillary number in shear flow is defined as:

$$
\mathrm{Ca}=\eta_{\mathrm{m}} \dot{\gamma} /\left(\Gamma_{\mathrm{d}, \mathrm{m}} / R\right)
$$

where $\eta_{\mathrm{m}}$ is the viscosity of the continuous phase, $\dot{\gamma}$ is the shear rate, $R$ is the radius of the droplet prior to undergoing 
deformation, and $\Gamma_{\mathrm{d}, \mathrm{m}}$ is the interfacial tension between the dispersed phase (droplets) and the continuous phase (matrix).

At a certain critical shear rate $\left(\dot{\gamma}_{c}\right)$, the viscous forces exceed the interfacial ones and the droplet is broken up. The capillary number corresponding to the critical shear rate $\left(\dot{\gamma}_{c}\right)$ is called the critical capillary number and is denoted by $\mathrm{Ca}_{(\text {crit })}$ with:

$$
\mathrm{Ca}_{\text {(crit) }}=\eta_{\mathrm{m}} \dot{\gamma}_{\mathrm{c}} /\left(\Gamma_{\mathrm{d}, \mathrm{m}} / R\right)
$$

The critical capillary number in pure shear flow is minimum when the viscosity ratio $(k)$ is equal to unity and increases to infinity for a viscosity ratio greater than 4 (ref. 4) (Fig. 1). Thus, systems with $k>4$ should not be dispersible in pure shear flow.

In elongational flow, the critical capillary number is defined by

$$
\mathrm{Ca}_{(\text {crit })}=\eta_{\mathrm{e}, \mathrm{m}} \dot{\varepsilon} /\left(\Gamma_{\mathrm{d}, \mathrm{m}} / R\right)
$$

where $\dot{\varepsilon}$ is the Hencky strain rate and $\eta_{\mathrm{e}, \mathrm{m}}$ is the elongational viscosity of the matrix. $\mathrm{Ca}_{(\text {crit) }}$ in elongational flow is lower and less sensitive to the viscosity ratio. Therefore, elongational flow fields are more effective than shear flow fields in transforming droplets into fibrous domains. More details on the theory of deformation in the case of newtonian and viscoelastic immiscible blends can be found in different review papers. ${ }^{5-8}$

At a given viscosity ratio $k$ with $(1 \leq k<4)$, different modes of deformation and breakup are possible, depending on the capillary number values:

$\mathrm{Ca}<0.1 \mathrm{Ca}_{\text {(crit) }}$, there is no deformation of the droplet. The interfacial energy dominates.

$0.1 \mathrm{Ca}_{\text {(crit) }} \leq \mathrm{Ca}<\mathrm{Ca}_{\text {(crit) }}$, the droplet deforms slightly without break-up and reach a stable form.

$\mathrm{Ca}_{\text {(crit) }} \leq \mathrm{Ca} \leq 2 \mathrm{Ca}_{\text {(crit) }}$, the viscous stress dominates the interfacial stress, the droplet is unstable and breakup occurs by the splitting of the droplet into two equal parts before elongation into a filament can be achieved.

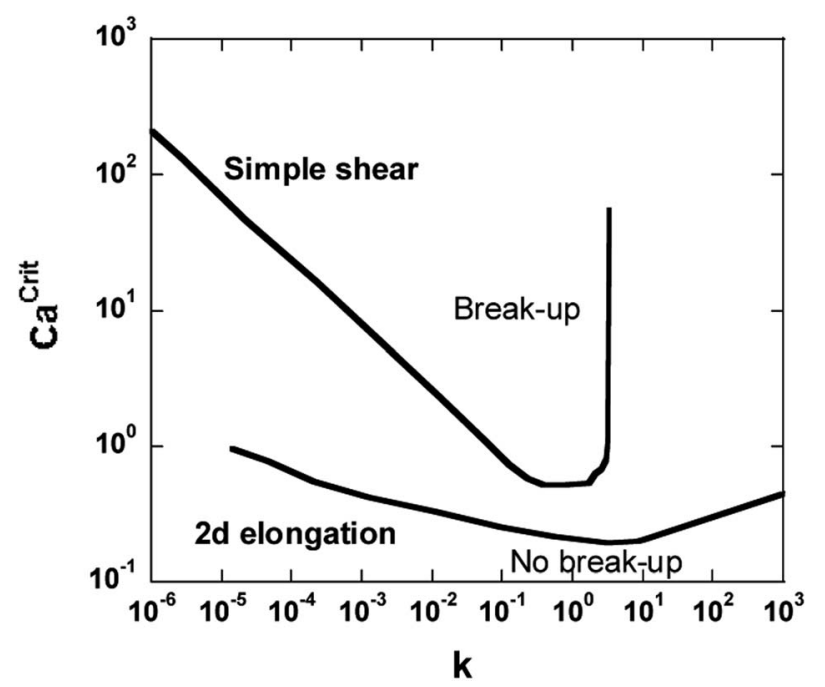

Fig. 1 The Grace curve gives the relation between the critical capillary number $\mathrm{Ca}_{(\text {(crit) }}$ and the viscosity ratio $k$ for the breakup of an initially spherical droplet in quasi-steady homogeneous flow (in simple shear and plane hyperbolic flow). ${ }^{4}$
$2 \mathrm{Ca}_{\text {(crit) }}<\mathrm{Ca} \leq 4 \mathrm{Ca}_{\text {(crit) }}$, the droplet is deformed into an unstable elongated fiber, then undergoes fragmentation via 'end-pinching' or Rayleigh capillary instabilities giving rise to several smaller droplets. ${ }^{9-12}$

$\mathrm{Ca}>4 \mathrm{Ca}_{\text {(crit) }}$, the interfacial stress is completely overwhelmed by the shear stress, leading to large deformation of droplets into long fibrils. In this case, the dispersed droplets form long stable fibrils. Many researchers have used these criteria to study/predict the morphology and fibril formation in polymer blends. ${ }^{\mathbf{1 3 , 1 4}}$

It is expected that in viscoelastic systems the critical capillary number also depends on the elasticity ratio. ${ }^{15-17} \mathrm{Wu}^{18}$ reports that the critical capillary number $\mathrm{Ca}_{(\text {crit })}$ is more important in the case of viscoelastic blends compared to newtonians ones. He proposes a V-shape describing the variation of $\mathrm{Ca}_{\text {(crit) }}$ as a function of the viscosity ratio $k$ as compared to the U-shape previously obtained in the case of newtonian melts. He also introduces an empirical equation between the critical capillary number and the viscosity ratio as:

$$
\mathrm{Ca}_{(\text {crit })}=4\left(\frac{\eta_{\mathrm{d}}}{\eta_{\mathrm{m}}}\right)^{ \pm 0.84}
$$

where, the exponent is positive if $\eta_{\mathrm{d}} / \eta_{\mathrm{m}}>1$ and negative if $\eta_{\mathrm{d}} / \eta_{\mathrm{m}}$ $<1$.

So elasticity of the droplet and matrix phases (often referred to as the first normal stress difference force $N_{1}$ ) should be an important factor affecting the morphology of the dispersed phase particles. Since the experimental measurements of the normal force $N_{1}$ are delicate, most studies devoted to the fibrillar morphology have focused on the effect of viscosity ratio neglecting the importance of the elasticity ratio between the dispersed and continuous phase, leading to contradictions and ambiguity to draw a clear correlation between the viscosity ratio and the optimal conditions of fiber formation and its temporal stability in the case of viscoelastic immiscible polymer blends. ${ }^{19-22}$ According to several literature reports, ${ }^{1,23-26}$ in the particular case of fiberlike morphology, the droplet-fibril transition could be controlled by the viscosity ratio $(k)$ between the dispersed phase and matrix (a more viscous matrix promotes the breakdown of droplets $\left.{ }^{27-31}\right)$, the elasticity ratio $\left(k^{\prime}\right)$ between the dispersed phase and matrix (a more elastic matrix promotes deformation and extension of the nodules into fibrils ${ }^{\mathbf{1 4 , 1 7 , 2 3 , 3 2 - 3 9}}$ ) and a compromise between deformation (shear or elongation) and relaxation should be achieved in order to have a stable filamentous morphology. ${ }^{21,22,40}$

Nevertheless, to summarize the results of the different studies on fibrillation ${ }^{\mathbf{4 1}}$ and according to the work of Van Oene, ${ }^{42}$ to promote the droplet/fiber transition, it is thus necessary to develop a system such as the viscosity ratio $k<4$ and in the same time the elasticity ratio $k^{\prime} \ll 1$. A fine fibrillar morphology will be formed when the interfacial tension between the matrix and the minor phase is low. ${ }^{43}$

But it is not only necessary to form the fibrillar morphology. This one must also be stable in the flow. Then, a dispersed phase with a long relaxation time favors the temporal stability of the fibrillar structure. ${ }^{21}$ 
Table 1 Chain extender $\ll C E \gg$ agent properties

\begin{tabular}{llllll}
\hline Name & Supplier & Trademark & $\begin{array}{l}\text { Apparent density } \\
\left(\mathrm{g} \mathrm{cm}^{-3}\right)\end{array}$ & $M_{\mathrm{w}}\left(\mathrm{g} \mathrm{mol}^{-1}\right)$ & $\begin{array}{l}\text { Epoxy content } \\
\left.(\mathrm{g} \mathrm{mol})^{-1}\right)\end{array}$ \\
\hline Joncryl & BASF & $4300 \mathrm{~F}$ & 1.08 & 5500 & 56
\end{tabular}

Table 2 Extrusion temperature profile

\begin{tabular}{lcccccccccc}
\hline Heating area & 1 & 2 & 3 & 4 & 5 & 6 & 7 & 8 & 9 & Die \\
\hline $\begin{array}{l}\text { Temperature }\left({ }^{\circ} \mathrm{C}\right) \\
\text { (PLA/PA11 blends) }\end{array}$ & 200 & 200 & 200 & 200 & 200 & 200 & 190 & 190 & 190 & 190 \\
$\begin{array}{l}\text { Temperature }\left({ }^{\circ} \mathrm{C}\right) \\
\text { (PLA/PA6 blends) }\end{array}$ & 230 & 230 & 230 & 230 & 230 & 230 & 230 & 225 & 220 & 220 \\
\end{tabular}

When a droplet undergoes high deformation in the matrix (reduced capillary number $\mathrm{Ca} / \mathrm{Ca}_{(\text {crit })}>1$ ), it is known that the fiber breakup is generated by the strong applied stresses during flow. However, it was observed that rupture can occur by surface instabilities. In particular, when $\mathrm{Ca} / \mathrm{Ca}$ (crit) $>2$, highly elongated long thread suspended in another liquid is under nonequilibrium conditions, and its stability depends on the flow conditions, the interfacial tension, and its proper rheological properties as well as those of the suspending medium. ${ }^{\mathbf{4 4}}$ When $\left(2<\mathrm{Ca} / \mathrm{Ca}_{(\text {crit }}<4\right)$, the capillary instabilities (called Rayleigh disturbances) are the predominant mechanism of the rupture (see the $\left.\operatorname{ESI}_{\dagger} \dagger\right)^{45}$

In simple shear flow with an affine deformation, Huneault et $a l .{ }^{46}$ give the following equation to estimate the breakup time of the fibril:

$$
t_{\mathrm{b}}=\left[\frac{\eta_{\mathrm{m}} \ln \left(\varepsilon / \varepsilon_{0}\right)}{\Gamma_{\mathrm{d}, \mathrm{m}} \Omega\left(k, \lambda_{\mathrm{m}}\right) \dot{\gamma}^{1 / 2}} \frac{R_{0}}{2}\right]^{2 / 3}
$$

or in a dimensionless form (reduced breakup time) as

$$
t_{\mathrm{b}}^{*}=\frac{t_{\mathrm{b}} \dot{\gamma}}{2 \mathrm{Ca}}=\frac{2}{\Omega\left(k, \lambda_{\mathrm{m}}\right)} \ln \left(\frac{0.81 R_{0}}{\varepsilon_{0}}\right)
$$

Thus, the self-induced fibrillar morphology results of a complex rheological and thermal process, in which the discontinuous phase can form a fibrous structure under specific rheological and processing conditions, which results in one polymer being reinforced or softened by the other one. The basis for the creation of a stable self-induced fibrillar morphology is controlled by the rheological and interfacial properties of the molten components (viscosity and elasticity ratios, and interfacial tension) which control the deformation mode of the dispersed phase and guarantee the droplet/fiber transition $^{24}$ and the relaxation of the fibrils which controls the stability of the morphology. ${ }^{4-51}$ Therefore, such materials called MFCs have attracted a great deal of interest and have been the subject during the last decade of several academic studies and industrial applications. ${ }^{52}$ Because they are exclusively based on thermoplastic polymers, these structured materials can provide an interesting solution to the problems of lightening to equivalent mechanical performances due to the low density of the polymer fiber while preserving the recyclability potential of the thermoplastic polymers.

Conventionally, the manufacture of these structured products is decomposed in two stages. The first step is the compounding of a blend of two immiscible polymers followed by drawing (hot or cold, i.e. above or below the glass transition temperature of the dispersed phase), cooling and quenching of the fibrillar morphology. The possibility of obtaining this morphology is directly related to the viscosity and elasticity ratios of the two materials, under the conditions induced by their flow in the extrusion and drawing processes. The second step, of forming process (by extrusion or injection) shall be carried out under conditions of temperature, strain rate deformation and residence time which do not to alter, or minimize the alteration of, the fibrillar structure previously obtained. For this purpose, the forming temperature of the dispersed phase must be $30{ }^{\circ} \mathrm{C}$ higher than that of the matrix. Thus, taking into account the constraints imposed on the one hand for obtaining the fibrillation of the dispersed phase during compounding and stretching and on the other hand for preserving the fibrillar structure during forming process, the number of polymers pairs suitable for these processes and showing an industrial interest is generally relatively limited.

Another approach is proposed here with the aim of extending the spectrum of polymer couples which can be used. The goal is to circumvent the constraints associated with the forming process stage by promoting fibrillation during this step and not only during the first compounding stage. This can be achieved, for example, by imposing a high stretching deformation in the feeding system of an injection mould. Thus, in the present study, a strategy is adopted consisting in the in situ generation, during the micro-injection forming process, of wellaligned high aspect ratio flexible nanofibrils having strong interfacial affinity with the matrix. Discussed here are blends of linear PLA (or chain branched modified PLA) and different polyamides (PA-11 and PA-6), which are chosen to form the

Table 3 Composition of PLA/PA6 and PLA/PA11 blends ( $j$ stands for chain extender agent)

\begin{tabular}{llll}
\hline Designation & Composition (wt\%) & Stretching ratio \\
\hline PLA/PA11-LV & 80 (PLA) & 20 (PA11-LV) & 6.2 \\
PLA-j/PA11-LV & 80 (PLA + 1\% joncryl) & 20 (PA11-LV) & 6.2 \\
PLA/PA11-HV & 80 (PLA) & 20 (PA11-HV) & 6.2 \\
PLA/PA6 & 80 (PLA) & 20 (PA6) & 6.2
\end{tabular}




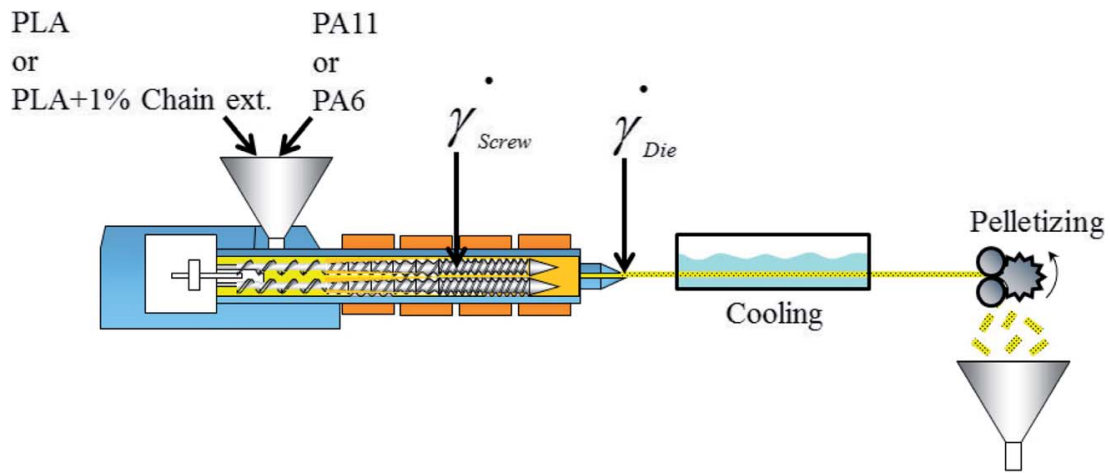

Fig. 2 Manufacturing process of polymer blends extrudates.

fibrillar phase because of their impressive ductility, as well as their good compatibility with PLA. ${ }^{.3,54}$

The present study addresses several key aspects concerning the development of fibrillar morphologies in a biobased polymer blends where nanometric poly(amide) fibrils could be

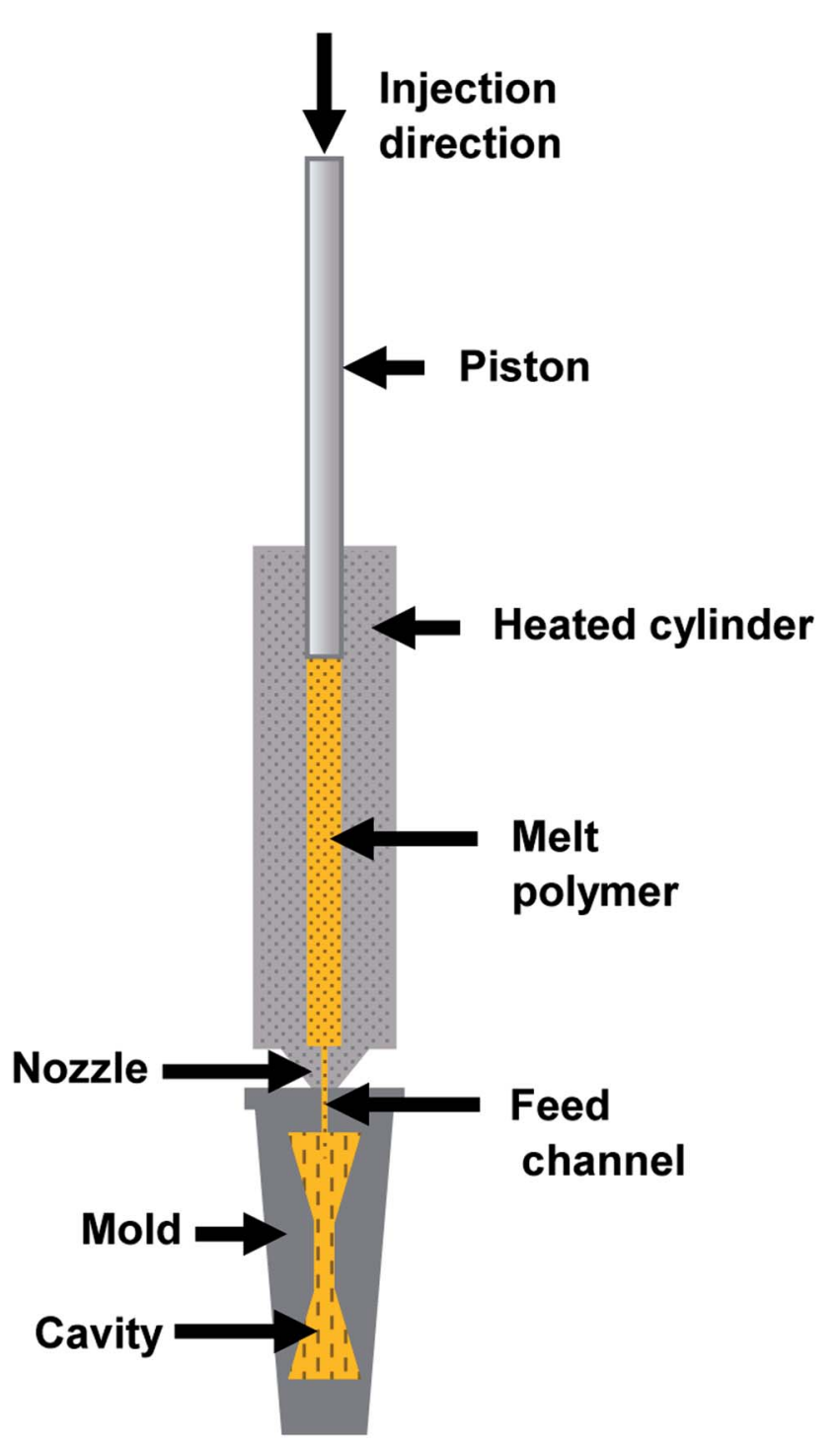

Fig. 3 Schematic illustration of the piston micro-injection process. controlled by processing parameters and rheology of neat polymers. In this respect, the article exposes and discusses several results such as: (i) the control over nanometric PA11 fibrils by viscosity and elasticity ratio, (ii) the identification of a critical shear rate and (iii) the use of reactive extrusion to generate PA11 (nano)fibrils at low shear rates. For this purpose, a precise shear rate characterization was accessed in injectionmolding by high-speed image analysis and, on another side, normal stress differences of neat polymers were approached by two different methods. The correlation between viscoelastic properties of blend components, morphological structure and ultimate properties of the in situ polymer composites with a specific focus on the role of the matrix elasticity was highlighted.

\section{Experimental}

\subsection{Materials}

A semi-crystalline aliphatic polyester poly(l-lactic acid) (PLLA) (4032D, NatureWorks, USA) with a melting temperature of $170{ }^{\circ} \mathrm{C}$ is used as matrix. It has a d-lactide content of $1.4 \pm 0.2 \%$, a residual lactide content lower than $0.3 \%$, a solid density of $1.24 \mathrm{~g} \mathrm{~cm}^{-3}$ and a melt flow index of $7 \mathrm{~g} / 10 \mathrm{~min}$ measured at $210{ }^{\circ} \mathrm{C}$ under load of $2.16 \mathrm{~kg} .{ }^{55}$

Two polyamides 11 (PA11) with different viscosities having a solid density of $1.03 \mathrm{~g} \mathrm{~cm}^{-3}$ are chosen for the dispersed phase. The more viscous PA11, named PA11-HV (which stands for High Viscosity PA11) (Rilsan ${ }^{\circ}$ BESVO, Arkema, France) has a melting temperature of $189{ }^{\circ} \mathrm{C}$ and a melt volume-flow rate of about $6 \mathrm{ml} / 10 \mathrm{~min}$ at $235{ }^{\circ} \mathrm{C}$ under load of $2.16 \mathrm{~kg}$. The less viscous PA11, named PA-LV (which stands for Low Viscosity PA11) (Rilsan ${ }^{\circledR}$ BMNO, Arkema, France) has a melting temperature of $189{ }^{\circ} \mathrm{C}$ and a melt volume-flow rate of about $36,5 \mathrm{ml} /$ $10 \mathrm{~min}$ at $235{ }^{\circ} \mathrm{C}$ under load of $2.16 \mathrm{~kg}$ (that is nearly 6 times lower than that of PA-HV). A polyamide 6 (PA6) with a solid density of $1.13 \mathrm{~g} \mathrm{~cm}^{-3}$ (Akulon® PA6C, DSM, The Netherlands) is also chosen for the dispersed phase. It has a melting temperature of $220^{\circ} \mathrm{C}$ and an intrinsic viscosity of about $245 \mathrm{ml}$ $\mathrm{g}^{-1}$. All polymers were dried in a vacuum at $80{ }^{\circ} \mathrm{C}$ for at least $12 \mathrm{~h}$ to minimize the moisture content before processing.

In addition, a chain extender $\ll \mathrm{CE} \gg$ agent with multiple epoxy functions (Joncryl 4300F, BASF, Germany) (Table 1) is used in order to increase the viscosity and elasticity of PLA. The 

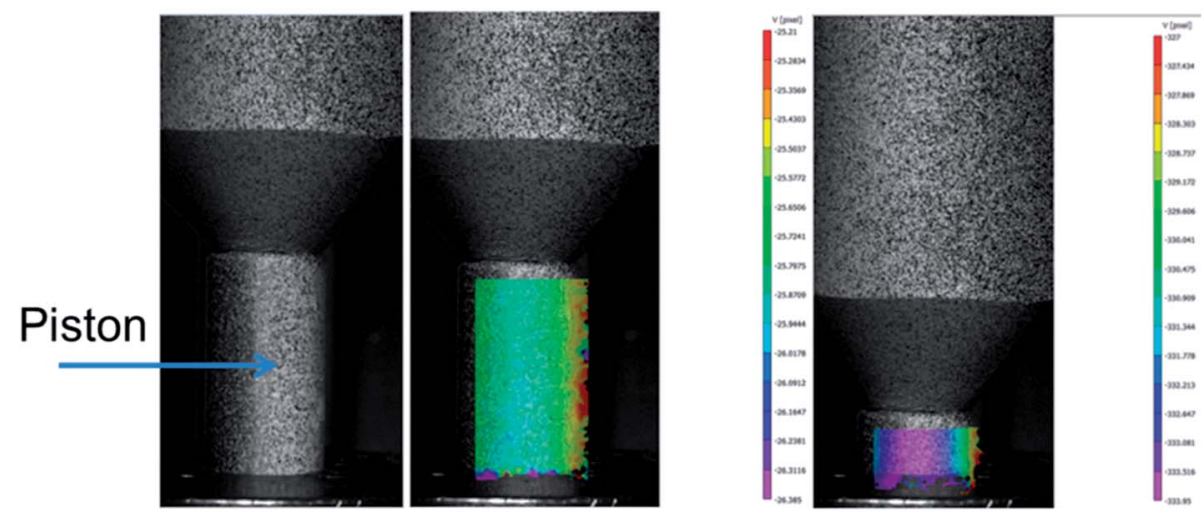

Fig. 4 Schematic illustration of the digital image correlation during microinjection process.

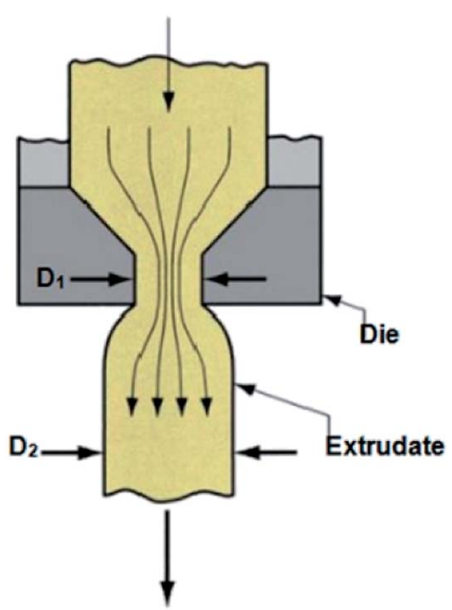

Extrudate swell $=D_{2} / D_{1}$

Fig. 5 Schematization of the extrudate swell measurement at the die exit.

notation PLA-j will designate the chain extender modified PLA. Before processing, all materials are dried at least 24 hours at $80{ }^{\circ} \mathrm{C}$ under vacuum in order to remove moisture.

\subsection{PLA modification by reactive extrusion}

Solid granules of PLA are first mechanically grinded to a micron sized powder by the conventional cryogenic milling (CM) process using a rotary knife mill (Pulverisette 19, Fritsch, The Netherlands) fitted with a $0.5 \mathrm{~mm}$ sieve (trapezoidal perforation) at a high rotational rotor speed of $3400 \mathrm{rpm}$. Throughout the pulverisation process, the pellets are continuously submerged within a bath of liquid nitrogen inducing the formation of very fine particles. The total milling time is estimated to be 15 seconds (one cycle) and the material throughput quantity is $\sim 1 \mathrm{Kg} \mathrm{h}^{-1}$.

After drying in a vacuum oven, some PLA powder is dry blended with $1 \%$ of chain extender $\ll \mathrm{CE} \gg$ agent and then extruded in a twin-screw extruder (HaakePolylab PTW 16/40, Thermo Scientific, Germany) at a temperature of $190{ }^{\circ} \mathrm{C}$. The throughput is set at $0.75 \mathrm{~kg} \mathrm{~h}^{-1}$ and the screw speed at $80 \mathrm{rpm}$. Finally, the PLA-chain extender blend (designed by PLA-j) is quenched in water and pelletized. With those operating parameters, the residence time in the extruder ranges from 3 to 5 minutes and the material temperature reaches $205{ }^{\circ} \mathrm{C}$ in the die. Considering the chain extender reaction kinetics (supplier data), a conversion rate of $99 \%$ is expected.

\subsection{Melt-blending}

PLA/PA 80/20 w/w blends are first prepared by dry-blending, then extruded in the same twin-screw extruder as before. A screw speed of $150 \mathrm{rpm}$ and a throughput of $0.7 \mathrm{~kg} \mathrm{~h}^{-1}$ are maintained for all the blends. A specific decreasing temperature profile (Table 2) is set in order to quickly melt the polymers and then operate a slight cool down, enabling the strand to have sufficient viscosity to withstand the upcoming drawing process. Hence, this temperature profile brings a material temperature in the die of $\sim 195{ }^{\circ} \mathrm{C}$ in the case of PLA/PA11 blends and $\sim 226{ }^{\circ} \mathrm{C}$ in the case of PLA/PA6 blends. After the extruder exit, the strand is cooled in a water bath and stretched in a pelletizer used as a drawing device at $25 \mathrm{~m} \mathrm{~min}^{-1}$ which represents the highest achievable speed without compromising the strand integrity. The measurement of the diameter of the die $\left(D_{0}\right)$ and of the stretched strands $\left(D_{\mathrm{f}}\right)$ allows determining the stretching ratio $\left(D_{0}{ }^{2} / D_{\mathrm{f}}{ }^{2}\right)$ (6.2 in this particular case). Table 3 summarizes the different blends obtained. Samples are designated by PLA/ PA11-LV, PLA/PA11-HV and PLA/PA6 where LV and HV indicate Low Viscosity and High Viscosity polyamide 11 respectively.

In conditions used for melt blending (Fig. 2), the apparent shear rate in the extruder die, $\dot{\gamma}_{\text {die }}$, is calculated using the following equation ${ }^{56}$

Table 4 Total, polar, and dispersive components of the surface energy of neat polymers measured at $21^{\circ} \mathrm{C}$

\begin{tabular}{lllll}
\hline Samples & $\begin{array}{l}\gamma \text { polar } \\
\left(\mathrm{mN} \mathrm{m}^{-1}\right)\end{array}$ & $\begin{array}{l}\gamma \text { dispersive } \\
\left(\mathrm{mN} \mathrm{m}^{-1}\right)\end{array}$ & $\begin{array}{l}\text { Total surface energy } \\
\left(\mathrm{mN} \mathrm{m}^{-1}\right)\end{array}$ & $\begin{array}{l}\text { Polarity } \\
\text { ratio }\end{array}$ \\
\hline PLA & 4.0 & 32.8 & 36.8 & 0.11 \\
PA11 & 3.5 & 27.2 & 30.7 & 0.11 \\
PA6 (ref. 68) & 14.5 & 37.4 & 51.9 & 0.28
\end{tabular}


Table 5 Total, polar, and dispersive components of the surface energy of neat polymers extrapolateds 200 and $230{ }^{\circ} \mathrm{C}$

\begin{tabular}{|c|c|c|c|c|c|}
\hline Samples & $\mathrm{T}\left({ }^{\circ} \mathrm{C}\right)$ & $\begin{array}{l}\gamma \text { polar } \\
\left(\mathrm{mN} \mathrm{m}^{-1}\right)\end{array}$ & $\begin{array}{l}\gamma \text { dispersive } \\
\left(\mathrm{mN} \mathrm{m}^{-1}\right)\end{array}$ & $\begin{array}{l}\text { Total surface } \\
\text { energy }\left(\mathrm{mN} \mathrm{m}^{-1}\right)\end{array}$ & $\begin{array}{l}-\mathrm{d} \gamma / \mathrm{d} T \\
\left(\mathrm{mN} \mathrm{m}{ }^{-1}{ }^{\circ} \mathrm{C}\right)\end{array}$ \\
\hline PLA & 200 & 2.8 & 23.2 & 26.0 & 0.060 (ref. 59) \\
\hline PA11 & 200 & 2.1 & 16.9 & 19.0 & 0.065 (ref. 69) \\
\hline PA6 & 230 & 10.7 & 27.7 & 38.4 & 0.065 (ref. 58) \\
\hline
\end{tabular}
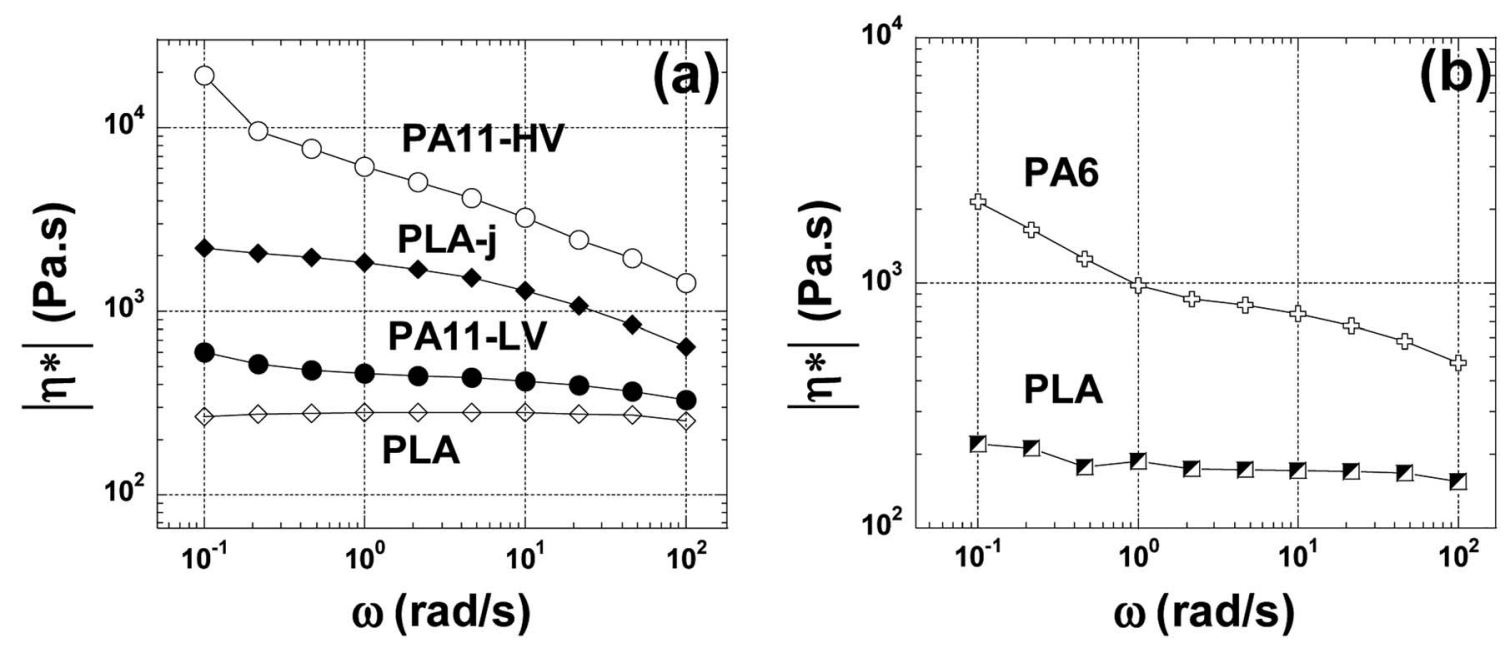

Fig. 6 The complex viscosity angular frequency dependence at $200{ }^{\circ} \mathrm{C}$ for neat, modified PLA and PA11 samples (a) and for neat PLA, PA6 at $230{ }^{\circ} \mathrm{C}(\mathrm{b})$.

$$
\dot{\gamma}_{\mathrm{die}}=\frac{4 Q_{\mathrm{v}}}{\pi\left(r_{\mathrm{die}}\right)^{3}} \approx 80 \mathrm{~s}^{-1}
$$

where $r_{\text {die }}$ is the die radius $(\sim 1.6 \mathrm{~mm})$ and $Q_{\mathrm{V}}$ is the volumetric flow rate $\left(\sim 0.27 \mathrm{~cm}^{3} \mathrm{~s}^{-1}\right)$. It is worth mentioning that the shear rate over the flight of the screw is around $40 \mathrm{~s}^{-1}$ and is calculated using eqn (8): ${ }^{51}$

$$
\dot{\gamma}_{\text {screw }}=\frac{\pi D N}{60 h} \approx 40 \mathrm{~s}^{-1}
$$

where $D$ is the screw diameter, $N$ is the screw revolutions per second and $h$ is the average gap of the screw channel.

\subsection{Injection-moulding}

Specimens of the different compounds with different geometries (disks and dumbbells) are injection-moulded (HAAKE MiniJetII Piston Injection Moulding System, Thermo Scientific, Germany). The injection moulding temperature is set at $180{ }^{\circ} \mathrm{C}$ and $220{ }^{\circ} \mathrm{C}$ for PLA/PA11 and PLA/PA6 blends respectively. The injection pressure is set at 900 bars for $1 \mathrm{~s}$, and the holding pressure is set at 500 bars for $5 \mathrm{~s}$. The mould temperature is set at $40{ }^{\circ} \mathrm{C}$.

In order to investigate the link between the morphology of the micro-injection moulded parts and the rheological properties of used polymers, the shear rate during the micro-injection moulding process must be evaluated. A schematic illustration of the injection moulding system is presented in Fig. 3. During injection moulding, the polymer melt in the heated cylinder is transfered into the hot mould under high hydraulic pressure imposed by the piston. In order to evaluate the shear rate applied in the feed channel $\left(\dot{\gamma}_{\text {inj }}\right)$ located at the inlet of the mould cavity (Fig. 3), the piston speed should be measured. To do that, a digital image correlation (DIC) technique is used (Fig. 4). The 2D DIC system (vic-snap 2010, Correlated Solutions Ins, USA) measures the 2D displacement field of the piston

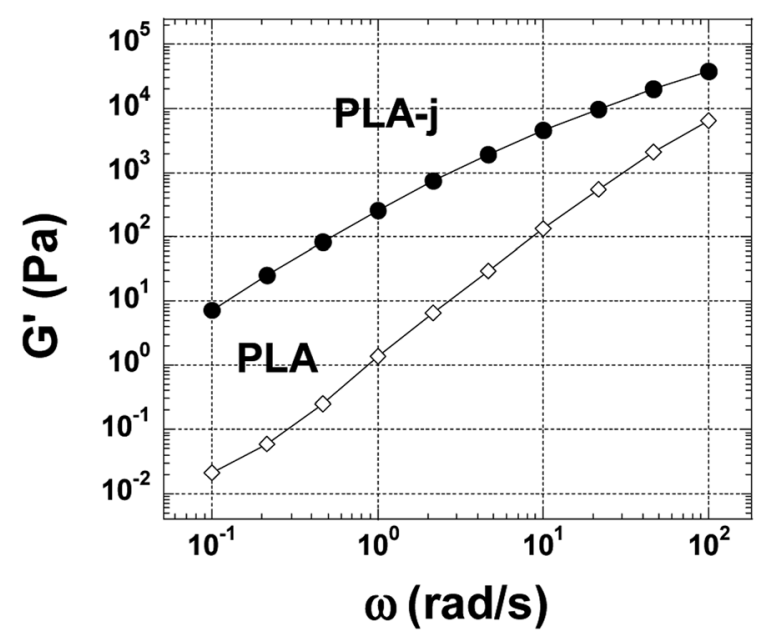

Fig. 7 Shear storage moduli at $200^{\circ} \mathrm{C}$ for neat and modified PLA. 

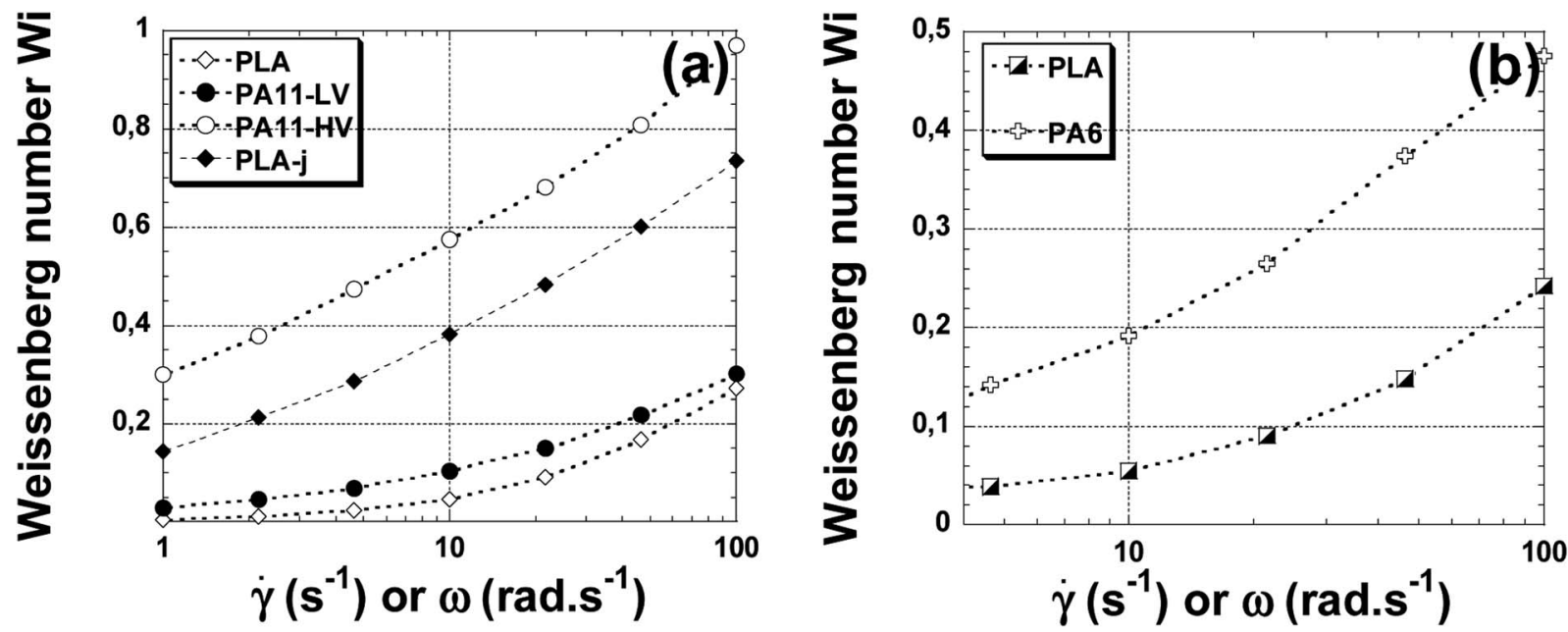

Fig. 8 The Weissenberg number versus angular frequency at $200{ }^{\circ} \mathrm{C}$ (a) for neat PLA, PA11, PLA-j samples; at $230{ }^{\circ} \mathrm{C}$ (b) for neat PLA and PA6 samples.

during the thrust of the material, based on images from one camera (AVT Pike F-421B, CCD captor, square pixel size $7.4 \mu \mathrm{m}$, resolution $4 \mathrm{MP}$ and acquisition speed in full resolution $16 \mathrm{ips}$ ). In order to use the DIC technique, a matt random speckle pattern is printed with a fine black liner on the front side of the piston prior to testing. The framing rate is 10 frames per second. The DIC data is post-processed with a subset size of 19 $\times 19$ pixels and a grid point spacing of 5 pixels (vic 2D 2010, Correlated Solutions Inc, USA).

Knowing the dimensions of the injection moulding piston $(\varphi$ $=11 \mathrm{~mm})$ and of the feed channel $\left(2 \times 1 \mathrm{~mm}^{2}\right)$, then the volumetric flow rate in the feed channel (called runner) is calculated following the eqn (9). Furthermore, it is possible to calculate the shear rate following the eqn (10). ${ }^{56}$

$$
Q_{\mathrm{v}}=V^{\text {piston }} \times \pi \times\left(\frac{D^{\text {piston }}}{2}\right)^{2}=2852 \mathrm{~mm}^{3} \mathrm{~s}^{-1}
$$

$$
\dot{\gamma}_{\text {inj }}=\frac{6 \times Q_{\mathrm{v}}}{w h^{2}}=8553 \mathrm{~s}^{-1}
$$

where $V^{\text {piston }}$ and $D^{\text {piston }}$ is speed and diameter of the injection moulding piston respectively, $w$ is the feed channel width and $h$ is its height. These calculations give an average injection moulding shear rate equal to $8553 \mathrm{~s}^{-1}$.

\section{Characterization}

\subsection{Interfacial tension assessment}

Surface energy of each polymer component (except PLA-j) is determined at $21^{\circ} \mathrm{C}$ with the sessile drop method, using a drop shape analyser (DSA4, KrüssGmbh, Germany). From contact angle measurements performed with water and diiodomethane as probe liquids, the total surface energy, as well as disperse and polar parts are determined by using Owens-Wendt regression method. ${ }^{57}$ On each measurement, ten drops of each liquid are
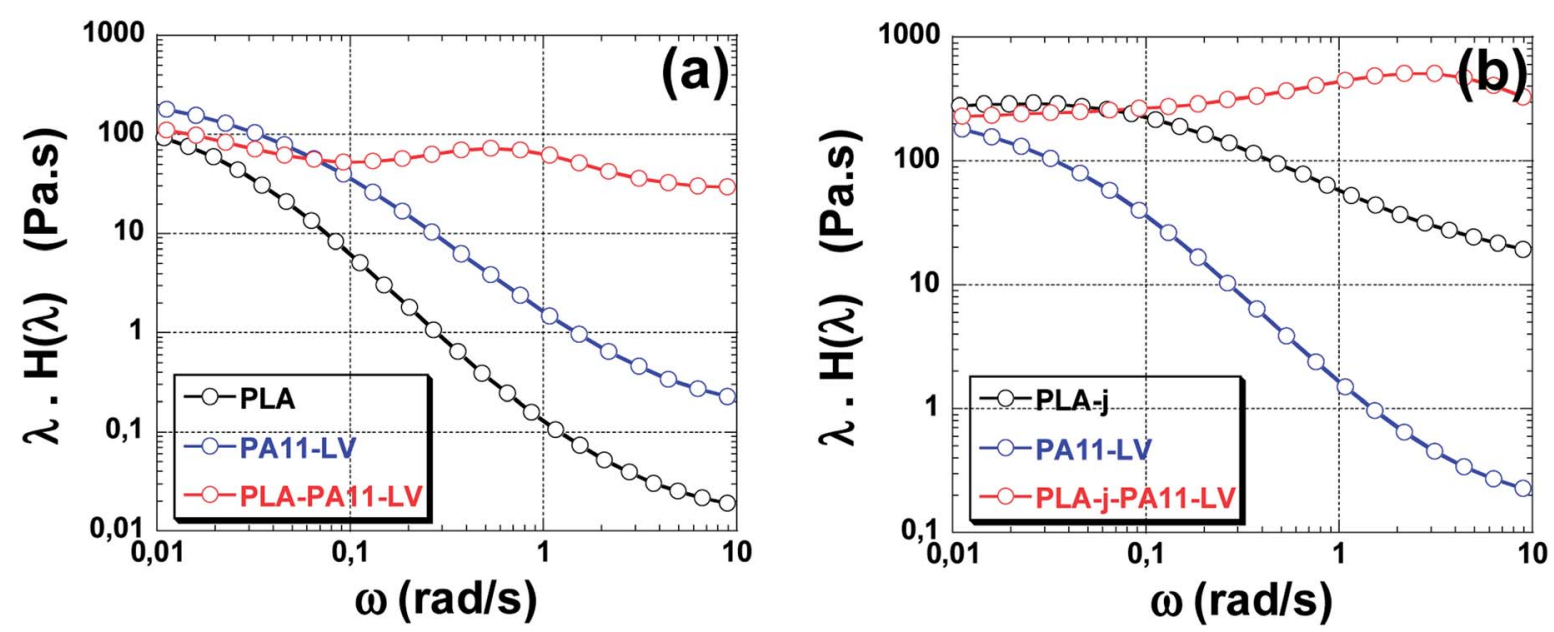

Fig. 9 Weighted relaxation spectrum of neat PLA and PLA/PA11-LV blends (a), neat PLA-j and PLA-j/PA11-LV blends (b). 


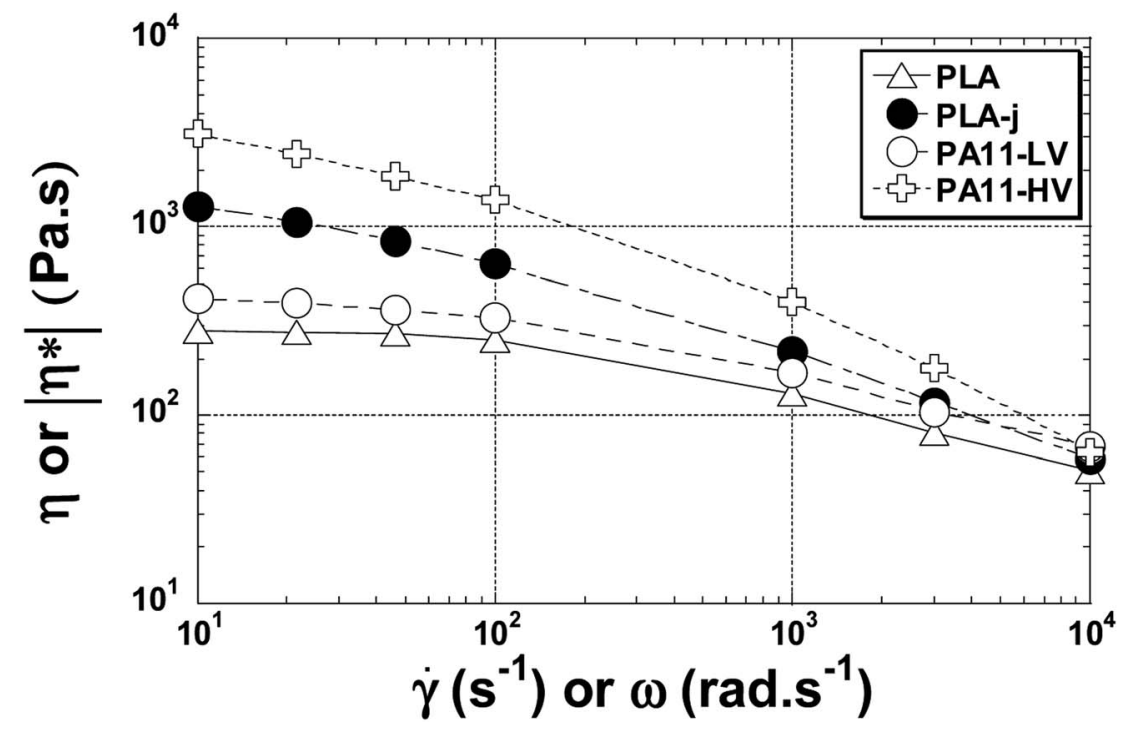

Fig. 10 The viscosity shear rate dependence at $200{ }^{\circ} \mathrm{C}$ for neat, modified PLA and PA11.

deposited and measured over the whole surface to ensure reproducibility at laboratory temperature.

Since melt blending is necessarily carried out at elevated temperatures, the surface energies and interfacial tensions must be known at common melt temperature. To calculate the surface energy at the melt processing temperature $\left(200{ }^{\circ} \mathrm{C}\right.$ for PLA/PA11 blends) and (230 ${ }^{\circ} \mathrm{C}$ for PLA/PA6 blends), a constant polarity ratio (the ratio of polar part to total surface energy) is assumed $^{58}$ as well as a thermal coefficient of surface tension $-\frac{\mathrm{d} \gamma}{\mathrm{d} T}$ of $0.06 \mathrm{mN} \mathrm{m}^{-1}{ }^{\circ} \mathrm{C}^{-1}$ for $\mathrm{PLA}^{59}$ and of $0.065 \mathrm{mN} \mathrm{m}^{-1}{ }^{\circ} \mathrm{C}^{-1}$ for both polyamides grades. ${ }^{58}$ The melt interfacial tension $\gamma_{12}$ between components 1 and 2 at the processing temperature is then estimated according to the fractional polarity using the geometric mean equation proposed by Owens and Wendt: ${ }^{57}$

$$
\Gamma_{12}=\gamma_{1}+\gamma_{2}-2 \sqrt{\gamma_{1}^{\mathrm{d}} \gamma_{2}^{\mathrm{d}}}-2 \sqrt{\gamma_{1}^{\mathrm{p}} \gamma_{2}^{\mathrm{p}}}
$$

where $\gamma_{1}$ and $\gamma_{2}$ refer to the surface free energy of two polymers and $\gamma^{\mathrm{d}}$ and $\gamma^{\mathrm{p}}$ refer to the dispersive part and polar part of the associated surface free energy, respectively.

For PLA-j/PA11-LV and PLA/PA11-LV, the interfacial tension $\left(\Gamma_{12}\right)$ at processing temperature is determined by Palierne model [34], using the SEM images analysis (Section 4.3), shear oscillation rheometry (Section 4.2) and relaxation times (Section 4.2) measurements:

$$
\Gamma_{12}=\frac{\eta_{\mathrm{m}} R(19 k+16)(2 k+3)}{40 \lambda(k+1)} \times\left[1+\Phi \frac{5(19 k+16)}{4(k+1)(2 k+3)}\right]
$$

where $\eta_{\mathrm{m}}$ is the matrix newtonian viscosity, $R$ is the radius of the inclusions, $\lambda$ is the interface relaxation time, $k$ is the viscosity ratio, and $\Phi$ is the volume fraction of the inclusion.

\subsection{Morphology analysis}

Blend morphology of the longitudinal cross section of the extruded and injection-moulded samples, is observed under

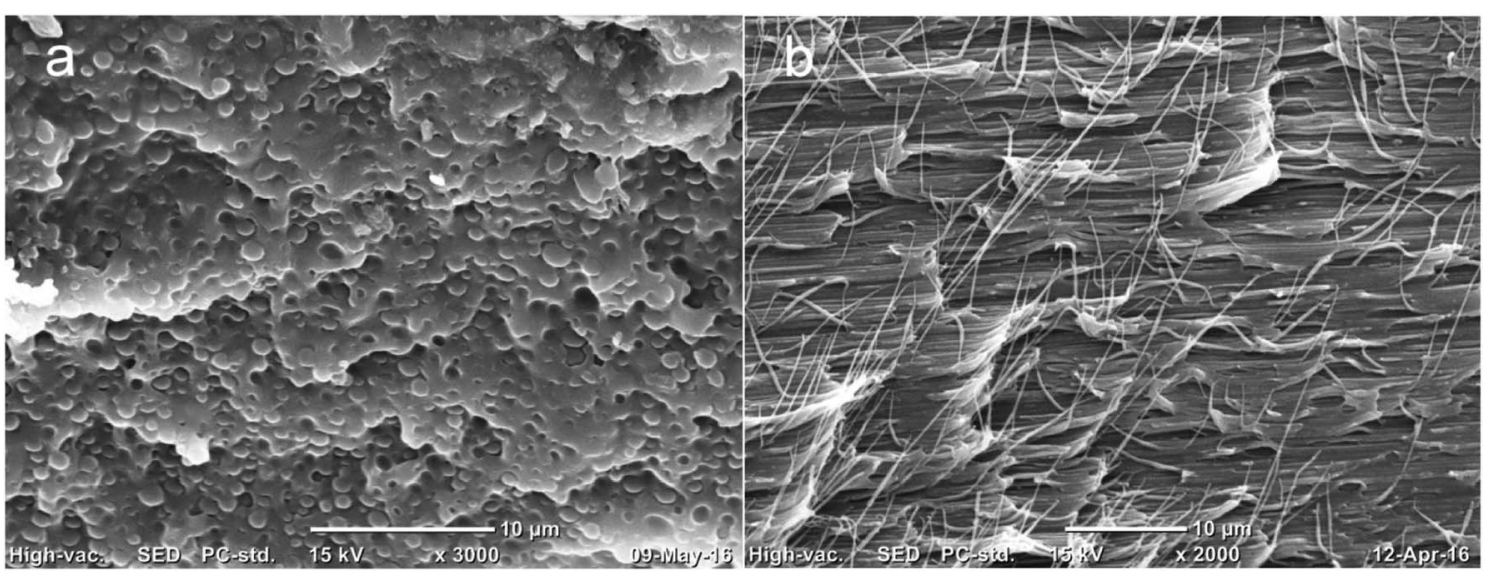

Fig. 11 SEM observation of longitudinal fracture surfaces of extrudates for (a) PLA/PA11-LV, (b) PLA-j/PA11-LV. 


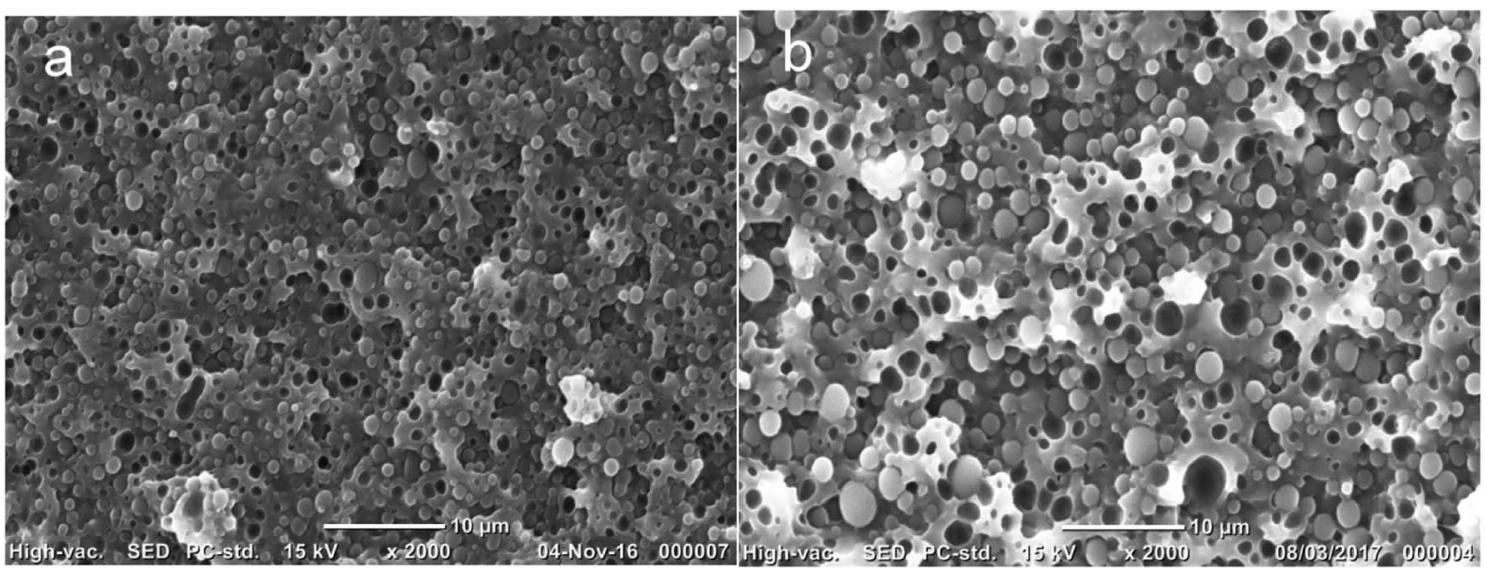

Fig. 12 SEM observation of longitudinal fracture surfaces of extrudates for (a) PLA/PA11-HV, (b) PLA/PA6.

Table 6 Average droplet diameter and polydispersity of PLA/PA blends

\begin{tabular}{lll}
\hline Blend & $\begin{array}{l}\text { Average droplet diameter } \\
\text { in the extrudate }(\mu \mathrm{m})\end{array}$ & FWHM $(\mu \mathrm{m})$ \\
\hline PLA/PA11-LV & 0.8 & 0.3 \\
PLA/PA11-HV & 0.9 & 0.4 \\
PLA/PA6 & 1.7 & 1.2 \\
PLA-j/PA11-LV & 0.3 & 0.1 \\
\hline
\end{tabular}

high vacuum with a scanning electron microscope (JEOL, JCM6000 Plus, Japan) operating at $15 \mathrm{kV}$ and a probe current of 130 pA. SEM micrographs of the PLA/PA blends are taken from samples fractured in liquid nitrogen for 3-5 min, and then coated with a thin gold layer (Polaron E5100 series II, Watford) to avoid charging on the fracture surface. The average PA domain diameters and their distribution are measured by means of image processing software (ImageJ@, USA).

\subsection{Shear oscillation rheometry measurements}

Dynamic rheological measurements are performed using a rotational rheometer (HAAKE MARS III, Thermo Scientific, Germany), equipped with $35 \mathrm{~mm}$ diameter parallel-plates geometry, with a $1.5 \mathrm{~mm}$ gap size. Injection-moulded disks obtained from micro-injection moulding are used for these tests after being dried in a vacuum oven at $80{ }^{\circ} \mathrm{C}$ during 24 hours prior to experiment. Measurements are performed in nitrogen atmosphere at $200{ }^{\circ} \mathrm{C}$ for PLA/PA11 blends and $230{ }^{\circ} \mathrm{C}$ for PLA/PA6 systems. Linear domains of the different materials are identified from strain sweeps and a common strain of $10 \%$ is chosen for all samples which is within the linear viscoelastic region. Frequency sweeps are carried out between 0.1 and 100 rad $\mathrm{s}^{-1}$. Dynamic storage modulus $\left(G^{\prime}\right)$, dynamic loss modulus $\left(G^{\prime \prime}\right)$, and complex viscosity $\left(\left|\eta^{*}\right|\right)$ are recorded as functions of angular frequency $(\omega)$. The relaxation spectra $H(\lambda)$ of neat polymers and blends are calculated. $H(\lambda)$ from the storage modulus vs. angular frequency data using the Tikhonov nonlinear regularization NLREG method integrated in the commercial software package RheoWin (ThermoScientific,

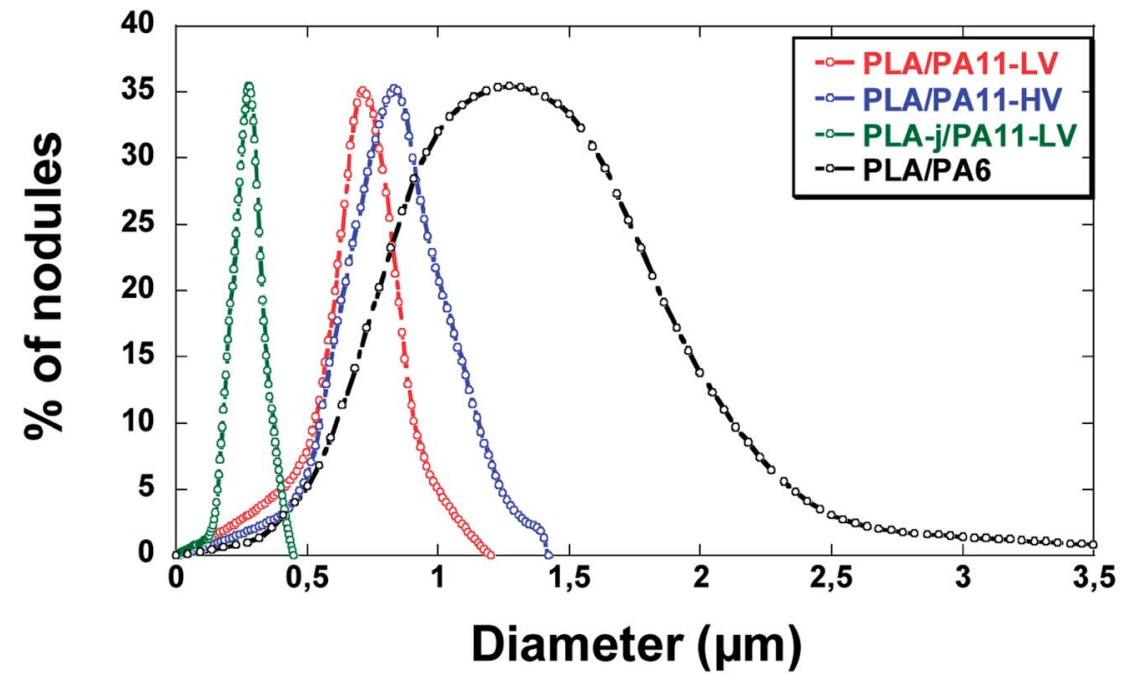

Fig. 13 Particle size distribution of PLA/PA blends. 


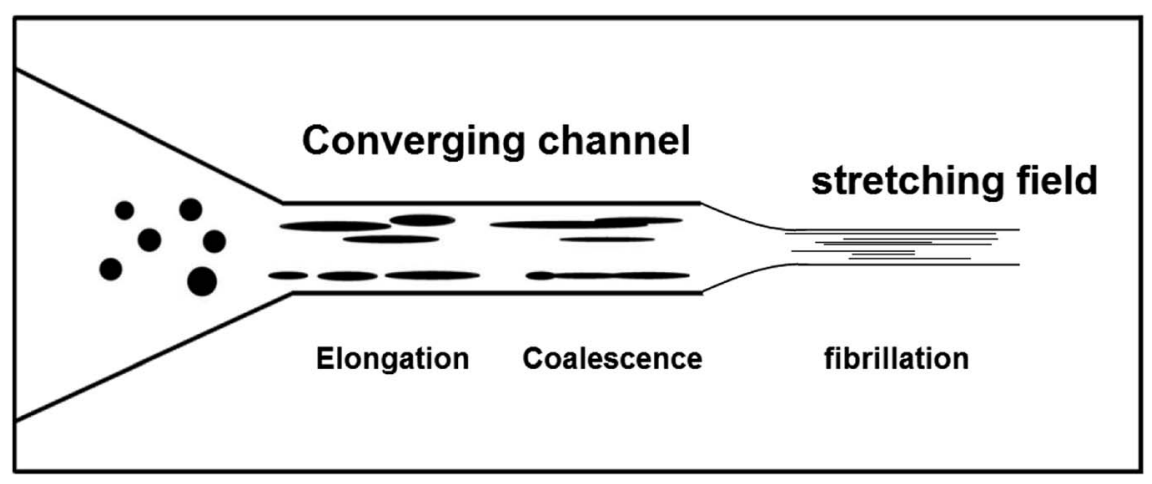

Fig. 14 Schematic illustration of morphological evolution of in situ nanofibrillar PLA-j-PA11 blends.

Table 7 Viscosity and elasticity ratios for PLA/PA11, PLA-j/PA11 and PLA/PA6 extrudate blends at $80 \mathrm{~s}^{-1}$ (in the extrusion die)

\begin{tabular}{lllrl}
\hline Blend system & $k$ & $\begin{array}{l}k^{\prime} \text { (elasticity ratio) } \\
\text { (based on Wi ratio) }\end{array}$ & $\begin{array}{l}k^{\prime} \text { (elasticity ratio) } \\
\text { (based on } G^{\prime} \text { ratio) }\end{array}$ & Type of morphology \\
\hline PLA/PA11-LV & 1.3 & 1.2 & 1.5 & Nodular \\
PLA/PA11-HV & 6.1 & 3.9 & 17.2 & Nodular \\
PLA/PA6 & 3.2 & 2.1 & 6.3 & Nodular \\
PLA-j/PA11-LV & 0.5 & 0.4 & 0.2 & Fibrillar
\end{tabular}

Germany) ${ }^{\mathbf{6 0}}$ which is a numerical procedures based on the regularization method proposed by Honerkamp and Weese, ${ }^{\mathbf{6 1}}$ following the eqn (13):

$$
G^{\prime}(\omega)=\int_{-\infty}^{+\infty} H(\lambda) \frac{\omega^{2} \lambda^{2}}{1+\omega^{2} \lambda^{2}} \mathrm{~d}(\ln \lambda)
$$

From the complex viscosity measurements, and assuming that the Cox-Merz rule $\left|\eta^{*}\right|(\omega)=\eta(\dot{\gamma})$ is applicable to estimate the viscosities of the matrix and the dispersed phase at the predominant shear rate in the melt blending equipment, $80 \mathrm{~s}^{-1}$, the viscosity ratio $(k)$ could be calculated.

Elasticity in the droplet or matrix phase could be represented by the first normal stress difference $N_{1}$. Consequently, the elasticity ratio can be calculated by:

$$
k^{\prime}=\frac{N_{1, \mathrm{~d}}}{N_{1, \mathrm{~m}}}
$$

where $N_{1, \mathrm{~d}}$ and $N_{1, \mathrm{~m}}$ are the first normal stress differences of the dispersed phase and the matrix respectively.

At very low frequency region $\left(\omega<10 \mathrm{rad} \mathrm{s}^{-1}\right)$, the elasticity $\left(N_{1}\right)$ is determined using the formula of Laun (eqn (15)). ${ }^{62}$

$$
N_{1}(\dot{\gamma})=2 G^{\prime}(\dot{\gamma})\left[1+\left(\frac{G^{\prime}(\dot{\gamma})}{G^{\prime \prime}(\dot{\gamma})}\right)^{2}\right]^{0.7}
$$

At high share rates $\left(\omega>1000 \mathrm{rad} \mathrm{s}^{-1}\right)$, the elasticity $\left(N_{1}\right)$ is deduced from the swell die measurements described below (Section 3.4, eqn (24)).

Elasticity ratio also can be characterized for each shear rate by the Weissenberg number (Wi) which is often used as criteria of melt elasticity. ${ }^{63}$ In simple shear flow, the Weissenberg number gives the ratio of the elastic forces over the viscous forces. In the case of a Maxwell fluid, the Weissenberg number can be written as

$$
\mathrm{Wi}=\lambda \dot{\gamma}
$$

where $\lambda$ is the Maxwell relaxation time and $\dot{\gamma}$ the shear rate.

Assuming that the Cox-Merz rule could be applied for all materials investigated here, $\lambda(\omega)=\lambda(\dot{\gamma})$ (with $\omega$ in $\operatorname{rad~s}^{-1}$ and $\dot{\gamma}$ in $\mathrm{s}^{-1}$ ), the elasticity of the polymers for each shear rate can be expressed as:

$$
\mathrm{Wi}(\dot{\gamma})=\lambda(\omega) \times \omega=\frac{\eta^{\prime \prime}(\omega)}{G^{\prime \prime}(\omega)} \omega=\frac{G^{\prime}(\omega)}{G^{\prime \prime}(\omega)}
$$

And then, the elasticity ratio for each shear rate can be calculated by:

$$
k^{\prime}=\frac{\mathrm{Wi}_{\mathrm{d}}(\omega)}{\mathrm{Wi}_{\mathrm{m}}(\omega)}
$$

between the Weissenberg number of the droplet phase $\left(\mathrm{Wi}_{\mathrm{d}}\right)$ and matrix $\left(\mathrm{Wi}_{\mathrm{m}}\right)$. Such a ratio is used by different authors ${ }^{63-65}$ to quantify the elastic properties of different viscoelastic polymer blends. A Weissenberg number lower than unity indicates viscous-dominant (i.e. liquid-like) behavior and values higher than unity indicate elastic-dominant (i.e. solid-like) behavior.

\subsection{Capillary rheometry measurements}

Apparent melt viscosities of the polymers at 200 and $230{ }^{\circ} \mathrm{C}$ are determined at 3 different apparent shear rates $\left(10^{3}, 10^{4}\right.$ and $10^{5}$ $\mathrm{s}^{-1}$ ) by using a capillary rheometer (Goettfert, Rheograph 75 Model, Germany) equipped with a capillary die having 
a diameter $(D)$ of $0.5 \mathrm{~mm}$ and a length $(L)$ of $10 \mathrm{~mm}(L / D$ ratio of $20)$. The entrance pressure $(\Delta P)$ is measured directly above the die entrance by a pressure transducer of $100 \mathrm{MPa}$. The rheometer cylinder is $25 \mathrm{~cm}$ long and $1 \mathrm{~cm}$ in diameter. Material can be extruded through the die at controlled linear piston velocity ranging from 0.01 to $20 \mathrm{~mm} \mathrm{~s}^{-1}$.

Die swell can also be calculated using the capillary rheometry measurements. When the temperature of the capillary rheometer reaches a stable level, the polymer is fed into the reservoir, and then tamped down to remove entrapped air. The piston speed is fixed to the desired shear rate and the measurements start $5 \mathrm{~min}$ after the beginning of the loading of the rheometer.

Extrudate swelling or die swell ratio is defined as the ratio of the extrudate diameter to the capillary die diameter ${ }^{66}$ (Fig. 5). Die swell is measured after the cooling of the hot extrudates of specified length. Swell measurements are performed after relaxation and complete elastic recovery of the strands. Since the diameter is measured after cooling, a correction factor is employed in order to normalize all swell data at the extrusion temperature rather than room temperature. ${ }^{67}$ Thus, the ratio of the extrudate diameter $\left(D_{2}\right)$ to the die diameter $\left(D_{1}\right)$ is multiplied by a density correction factor of: $\left(\frac{\rho_{\mathrm{s}}}{\rho_{\mathrm{m}}}\right)^{1 / 3}$ to calculate the extrudate swell or Barus effect $(B)$ as:

$$
(B)=\frac{D_{2}}{D_{1}}\left(\frac{\rho_{\mathrm{s}}}{\rho_{\mathrm{m}}}\right)^{1 / 3}
$$

where $\rho_{\mathrm{s}}$ and $\rho_{\mathrm{m}}$ are the solid and melt density respectively. The $1 / 3$ power is employed for isotropic materials. ${ }^{66,67}$ Swell measurements are evaluated at $200{ }^{\circ} \mathrm{C}$ and $230{ }^{\circ} \mathrm{C}$ for PLA, at $200{ }^{\circ} \mathrm{C}$ for PA11 samples, and at $230^{\circ} \mathrm{C}$ for PA6 samples.

Then, extrudate swell is used to calculate the first normal stress difference $\left(N_{1}\right)$ at high shear rate using the Tanner formula: ${ }^{66}$

$$
(B)=\left[1+\frac{1}{8}\left(\frac{N_{1}}{\dot{\eta}}\right)^{2}\right]^{1 / 6}
$$

Then:

$$
\left.N_{1}=\eta \dot{\gamma}\left(8\left[(B)^{6}-1\right)\right]\right)^{0.5}
$$

\subsection{Tensile tests}

Tensile properties are measured (Lloyd LR $10 \mathrm{~K}$, United Kingdom) at $23{ }^{\circ} \mathrm{C}$, at a constant crosshead speed of 10 $\mathrm{mm} \min ^{-1}$, with dumbbell-shaped specimens $(1.5 \mathrm{~mm}$ thickness) prepared from micro-injection moulding according to the ISO 527-2 standard. All specimens are previously conditioned for at least $48 \mathrm{~h}$ at $20 \pm 2{ }^{\circ} \mathrm{C}$ under a relative humidity of $50 \pm$ $3 \%$. At least, five specimens are tested for each material and the mean values and standard deviationsare calculated and reported.

\section{Results and discussion}

\subsection{Surface energy and interfacial tension at melt processing temperature}

The contact angles, surface energy and polarity ratio of the neat materials at ambient (measured) and processing temperatures (calculated using procedure described in Section 3.1) are summarized in Tables 4 and 5 .

A value of $\gamma_{\text {PLA/PA11 }} \approx 0.6 \mathrm{mN} \mathrm{m}^{-1}$ is found at $200{ }^{\circ} \mathrm{C}$, suggesting a strong compatibility between the two immiscible polymers. In the case of PLA/PA6 blends, the melt interfacial tension at $230^{\circ} \mathrm{C}$ is $3.1 \mathrm{mN} \mathrm{m}^{-1}$ which is coherent with the fact that PA6 is much more polar than PLA.

Finally, using eqn (12) and the results of the morphology analysis, a melting interfacial tension of $0.87 \mathrm{mN} \mathrm{m}^{-1}$ can be calculated for PLA/PA11-LV blend. This value is in agreement with the estimated interfacial tension based on the fractional polarity theory described before. The interfacial tension for PLA-j/PA11-LV blend is $0.44 \mathrm{mN} \mathrm{m}^{-1}$, which is in accordance with the fine morphology found for this blend (domain size for PA11 discrete phase was less than $0.3 \mu \mathrm{m}, \S 4.3)$.

\subsection{Melt rheological behavior}

Fig. 6(a) shows the magnitude of the complex viscosity versus angular frequency at $200{ }^{\circ} \mathrm{C}$ of pure polymers used (PLA, the two grades of PA11 and PLA-j). In this range of frequency (0.1-100 $\operatorname{rad~} s^{-1}$ ), pure PLA presents almost a newtonian behavior. The onset frequency of shear-thinning is located at $60 \mathrm{rad} \mathrm{s}^{-1}$. Furthermore, compared to pure PLA, a drastic increase of complex viscosity is noted for PLA modified by $1 \mathrm{wt} \%$ of chain extender $\ll \mathrm{CE} \gg$. The onset frequency of shear-thinning is shifted to $8 \mathrm{rad} \mathrm{s}^{-1}$ in the $\ll \mathrm{CE} \gg$ modified PLA. This could indicate the presence of branched structures in addition to linear ones. In addition, an increase in the elasticity is also observed for modified PLA (Fig. 7) manifested by a noticeable increase in the shear modulus $\left(\mathrm{G}^{\prime}\right)$ in the whole considered angular frequency range. The introduction of chain branches due to chain extending reactions could explain the increase in melt viscoelasticity. ${ }^{70,71}$ PA11-LV and PA11-HV show a typical non-newtonian shear thinning viscosity profile with a similar onset frequency of shear-thinning at $10 \mathrm{rad} \mathrm{s}^{-1}$. In addition, in the whole examined angular frequency range, PA11-HV demonstrates a high melt viscosity and no newtonian plateau is observed. This result is consistent with the fact that PA11-HV has a high molecular weight compared to PA11-LV. At very low frequency, an unusual increase in the complex viscosity is observed in both PA11-LV and PA11-HV specimens probably

Table 8 Reduced breakup time and characteristic time for flow induced deformation of different PLA/PA blends

\begin{tabular}{lll}
\hline Blend system & Reduced breakup time $t_{\mathrm{b}}^{*}$ & $(\dot{\gamma})^{-1}$ \\
\hline PLA/PA11-LV & 34.5 & 0.0125 \\
PLA/PA11-HV & 82.0 & \\
PLA/PA6 & 49.1 & \\
PLA-j/PA11-LV & 27.6 &
\end{tabular}


due to the post-condensation of polyamide chains which occurred with increasing time since the frequency sweep is started at the highest frequency. ${ }^{72}$ Fig. 6(b) presents the complex viscosity of neat PLA and PLA/PA6 blends at $230{ }^{\circ} \mathrm{C}$. PLA matrix at $230{ }^{\circ} \mathrm{C}$ shows a quasi-newtonian viscosity curve in the range 1 to $100 \mathrm{rad} \mathrm{s}^{-1}$. At low frequencies $\left(\omega<1 \mathrm{rad} \mathrm{s}^{-1}\right)$, a slight increase in the viscosity is highlighted. An increase in viscosity would mean an increase in molecular weight arising from further polycondensation. Similar behavior is observed in the case of PA6. This change in melt viscosity due to postcondensation reaction is characteristic of polyamide $6 .^{73}$ It is useful to note that the onset frequency of shear-thinning at $230{ }^{\circ} \mathrm{C}$ is 50 and $15 \mathrm{rad} \mathrm{s}^{-1}$ for PLA, and PA6 respectively.

Fig. 8(a) shows the dependency of Weissenberg number (Wi) versus the shear rate for the neat and $\ll \mathrm{CE} \gg$ modified PLA matrix, low viscosity and high viscosity polyamide 11 . It can be seen that for all materials, the (Wi) numbers increases as the shear rate increases since the elastic character of viscoelastic polymers increases as the shear stress increases. In the whole domain of shear rate or frequencies, the higher values of (Wi) are obtained in the presence of PA11-HV. The low viscosity polyamide 11 (PA11-LV) presentes a lower elasticity compared to PA11-HV but it shows a higher elasticity by looking at neat PLA matrix. It is useful to note that $\ll \mathrm{CE} \gg$ modified matrix (PLA-j) presents a melt elasticity almost three times higher than the unmodified PLA. At $100 \mathrm{rad} \mathrm{s}^{-1}$, the Weissenberg number increases from 0.27 in the case of neat PLA to 0.73 in the case of PLA-j.

Fig. 8(b) shows the dependence of Weissenberg number on shear rate for PLA and PA6. For all polymers studied, the (Wi) number increases as $(\dot{\gamma})$ increases. The high viscosity polyamide 6 exhibits the highest values of (Wi) in the whole range of the examined angular frequency.

Fig. 9(a) shows the weighted relaxation spectrum of neat PLA, PA11-LV and PLA/PA11-LV blend. It is well documented in the literature that the relaxation time of pure PLA above its melting temperature is around $10^{-2} \mathrm{s.}^{74,75}$ Zhou et al. ${ }^{76}$ found that the peak relaxation time for PLA (grade 4032D, such as the one used in the present study) is located at $10^{-2} \mathrm{~s}$ at $190{ }^{\circ} \mathrm{C}$. Similar results $\left(\lambda=10^{-2} \mathrm{~s}\right)$ are found by Najafi et al. and Walha et al. on PLA (grade 3001D) at $200{ }^{\circ} \mathrm{C}^{75,77}$ The relaxation of pure PA11-LV occurs also at high frequency (short relaxation times < $10^{-2} \mathrm{~s}$ ) as seen in Fig. 9(a) and cannot be identified in the frequency domain used in the present study. In the case of PLA/ PA11-LV blends, a large peak appears located at $0.62 \mathrm{~s}$. This peak detected at longer relaxation times is associated with the shape relaxation of the PA11 droplets.

Fig. 9(b) shows the relaxation spectrum of neat PLA, modified PLA containing $1 \%$ wt of $\ll \mathrm{CE} \gg$, and of PLA-j/PA11-LV blend. Two peaks can be easily identified, corresponding to two relaxation times. The first peak can be ascribed to the PLA-j matrix relaxation $(0.03 \mathrm{~s})$ which is 3 times higher than that of the unmodified PLA. Similar trend was found by Najafi et al. ${ }^{75}$ which correlated the increase in the relaxation time of chainextender modified PLA by an increase in the melt elasticity. The second peak detected at long relaxation times domain is characteristic of the form relaxation of droplets $(2.5 \mathrm{~s}$ in PLA-j/ PA11-LV compared to 0.62 in PLA/PA11-LV). ${ }^{78}$

The viscosity versus shear rate curve from the oscillatory rheometry measurement fit reasonably well with the viscosity data obtained using rod capillary rheometry. Actually, according to the Cox-Merz theory, ${ }^{79}$ the oscillatory complex dynamic viscosity $\eta^{*}$ as a function of angular frequency and the steady state viscosity $\eta$ as a function of shear rate can be superimposed for unfilled polymer melts, as shown in Fig. 10.

\subsection{Morphology of the blends in the extrudate}

Fig. 11 and 12 show the SEM micrographs of longitudinal fracture surfaces of extrudates of different blends. Table 6 summarizes the average diameter of PA droplets in the blends and Fig. 13 represents the droplet size distribution. FWHM (full width at half maximum) is also measured in order to evaluate the polydispersity of diameter values.

All the unmodified PLA based blends present a uniformly distributed nodular morphology. The average size of PA11-LV droplets is $0.8 \mu \mathrm{m}$ with a polydispersity FWHM of $0.3 \mu \mathrm{m}$ (Fig. 11(a)). The presence of the fine morphological structure in the PLA/PA11-LV strands confirms the good compatibility between PLA and polyamide $11 .^{54}$ The domain size of high viscosity polyamide 11 dispersed phase in the PLA-PA11-HV blend is slightly increased compared to that of the low viscosity PA11 (PA11-LV) with a nodule diameter in the range of 0.4-1.4 $\mu \mathrm{m}$ (averaged $0.91 \mu \mathrm{m}$ ). However, the droplet size varies more with a polydispersity FWHM of $0.4 \mu \mathrm{m}$ (Fig. 12(a)). Compared to PA11-LV particles, PA6 droplets are much larger, with a mean particle size around $1.7 \mu \mathrm{m}$ and the size distribution becomes wider (FWHM $\sim 1.2 \mu \mathrm{m}$ ). Compared to blends based on high viscosity polyamide 11 (PA11-HV), PLA/PA6 blend has a larger size distribution. The average diameters of PA6 nodules are almost twice larger than those of the PA11HV(Fig. 12(b)). This difference between PA11 and PA6 based blends may be caused by the different polarity of the macromolecular chains of PA6 and PA11 as claimed by the difference in the melt surface energy between two polymers: the interfacial tension increases from $0.6 \mathrm{mN} \mathrm{m}^{-1}$ in the case of PLA/PA11 blend to $3.1 \mathrm{mN} \mathrm{m}^{-1}$ in the case of PLA/PA6 system (Section 4.1).

In contrast, electron microscopy images of the blend prepared from the modified PLA using $\ll$ CE $\gg$ (PLA-j/PA11$\mathrm{LV})$ reveal the presence of a fibril/matrix morphology (Fig. 11(b)). Long PA11 nano-fibrils with large aspect ratios and diameters of $\sim 0.3 \mu \mathrm{m}$ are generated and are mainly parallel to each other along the extrusion direction. One can note the presence of some fibers not oriented in the direction of the flow direction, probably due to tearing during the cryo-fracture. The polydispersity of the fibrous domains is narrow with a FWHM of $0.1 \mu \mathrm{m}$.

To explain the fibrillation mechanism in the case of PLA-jPA11 extrudates where the matrix is more viscoelastic than the dispersed phase, one can assume that prior to the entry of the extruder die, the dispersed phase in the extruded melt is present predominantly in the form of small droplets (fine 


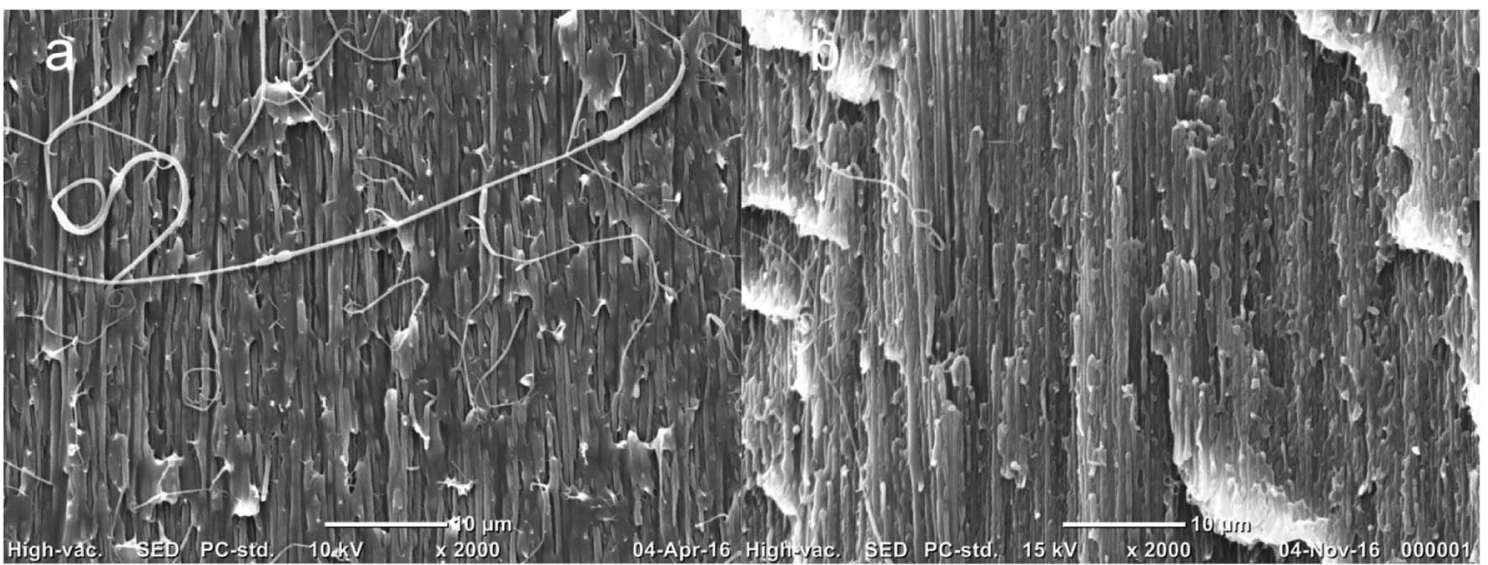

Fig. 15 SEM pictures of longitudinal fracture surfaces of micro-injection moulded parts for (a) PLA/PA11-LV, (b) PLA/PA11-HV.

nodular morphology). In the converging cross section at the die entrance, the extruded melt is subjected to a shear stress combined with an extensional stress. In this region, the droplets in the melt may elongate to a certain degree in the form of ellipsoids but do not fibrillize. However, once drawn by the external stretching device (Fig. 14), the droplets can elongate into fibrils under the uniaxial extensional stress since the more viscoelastic matrix can transmit the deformation stresses to the drops. One could also predict that the smaller droplets in the die entry region collide and can coalesce into larger droplets, and then they further extend into fibrils. ${ }^{80}$ Other authors have examined fibril formation in the converging die entrance and found droplet coalescence to occur there. ${ }^{30,80,81}$ In brief, in the case of the present study, the combined effect of deformation and coalescence leads to fibrillation of the PA11 dispersed phase droplets in viscoelastic PLA matrix modified by the $\ll \mathrm{CE} \gg$.

As reported in the Fig. 11(b) and Table 6, the PA11-LV fibrils exhibit a nanometric size distribution in the $\ll \mathrm{CE} \gg$ modified PLA matrix (PLA-j). This finer morphology (compared to that of unmodified PLA/PA11-LV blend) can be explained by the high compatibility between PA11 and PLA-j due to the low interfacial tension of PLA-j/PA11 blend as reported above (Section 4.1).

Table 7 summarized the values of the viscosity ratio $k$, the elasticity ratio $k$ and corresponding obtained morphology for different blends. In the case of PLA/PA11 blends, large difference in the values of $k$ and $k^{\prime}$ is found between the two type of polyamides. In the presence of low viscosity PA11-LV, the viscosity and elasticity ratio are slightly higher than unity. Although the viscosity of the PA11-LVis close to that of PLA matrix, the fact that the elasticity of the drop is higher than the elasticity of the matrix ( $k^{\prime}$ based on the elastic modulus ratio equals to 1.5), the development of a fibrous morphology does not occurs. So, the elasticity of neat PLA is not high enough to promote deformation and extension of the droplets into filaments. According to the approach of Mighri et al. ${ }^{82,83}$ in the case of immiscible viscoelastic blends, the maximum elongational deformation of the dropletsis reached when the elasticity ratio $k^{\prime} \leq 0.37$. In the case of the high viscosity PA11-HV, the viscosity ratio is very high $(k>6)$ and the elasticity ratio is greater than 4 , unfavorable to the generation of a fibril/matrix morphology. However, it should be noted that nodular morphology observed in the photomicrographs of PLA/PA11-HVextrudate is finely homogeneous. According to the literature, in a shear flow field, with viscoelasticity ratios $\left(k, k^{\prime}\right)>4$, the deformation and breakup of a higher elastic drop in a weakly elastic matrix is not reached, giving rise in the majority of cases to a coarse and heterogeneous morphology. ${ }^{23,24,42}$ Nevertheless, the PLA/PA11 systems exhibit a very low interfacial tension at the melt

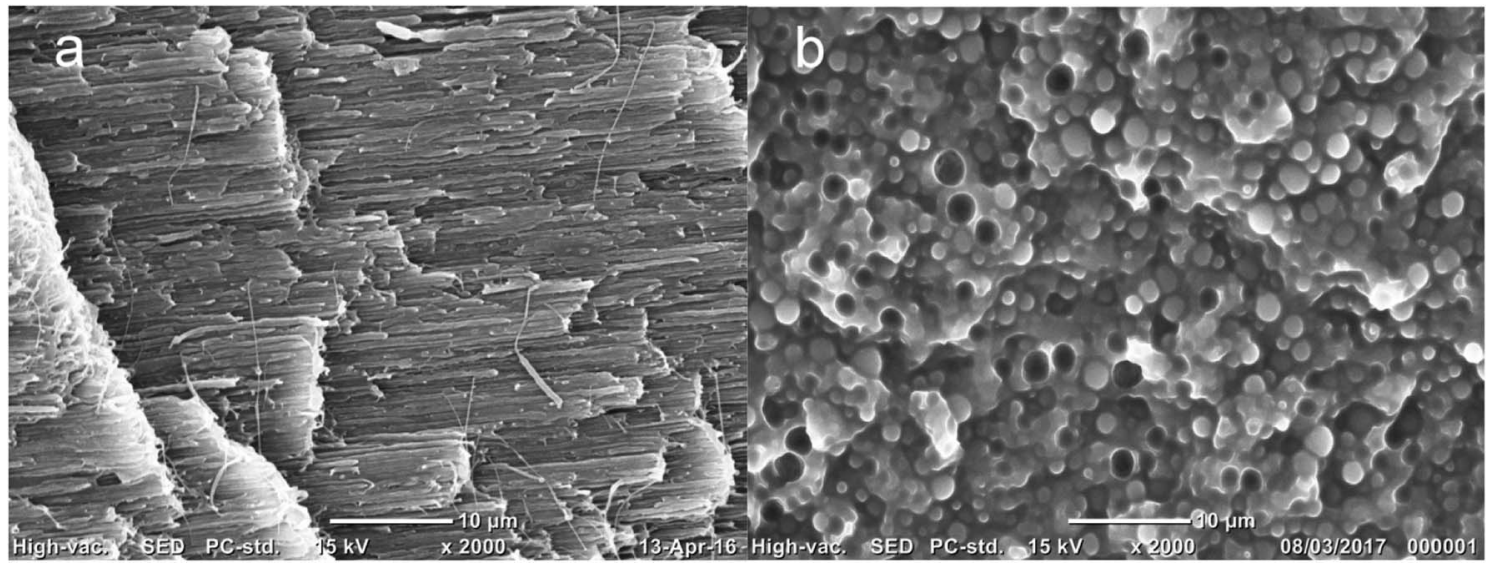

Fig. 16 SEM pictures of longitudinal fracture surfaces of micro-injection moulded parts for: (a) PLA-j/PA11-LV, (b) PLA/PA6. 
Table 9 The average droplet or fiber diameter of PA dispersed phase in micro-injection-moulded parts for PLA/PA11 and PLA/PA6 blends

\begin{tabular}{llll}
\hline Blend & $\begin{array}{l}\text { Average droplet diameter } \\
\text { in the injected part }(\mu \mathrm{m})\end{array}$ & FWHM $(\mu \mathrm{m})$ & $\begin{array}{l}\text { Average fiber diameter } \\
\text { in the injected part }(\mu \mathrm{m})\end{array}$ \\
\hline PLA/PA11-LV & & & 0.5 \\
PLA/PA11-HV & & & 0.3 \\
PLA/PA6 & 1.5 & 1.1 & 0.3
\end{tabular}

processing temperature $\left(\gamma_{\mathrm{PLA}, \mathrm{PA} 11} \leq 0.6 \mathrm{mN} \mathrm{m}^{-1}\right)$, which may partially explain the fine morphological structure obtained. In the case of PLA/PA6 extrudate blends, the viscosity and elasticity ratios are higher than 1 due to the weak viscoelasticity of neat PLA compared to PA 6. In these conditions, obtaining a fibrillar morphology is also not conceivable. In the case of PLA-j/PA11LVextrudate blends, suitable rheological conditions to the fibrillation are found corresponding to a dual viscosity and elasticity ratio $\ll 1$.

However, the structured materials are obtained during extrusion and the question of the stability of their morphology arises. ${ }^{84}$ Then, the reduced breakup time was calculated for different PLA/PA blends in the extrudates and compared to the characteristic time for flow induced deformation (the inverse of the shear rate in the die $\dot{\gamma}^{-1}$ ). The results are summarized in Table 8 . It can be seen that the reduced breakup time is widely higher than the residence time for all blends investigated, indicating that the nodular morphologies shown in PLA/PA extrudates is not due to the filaments capillary instabilities during shear flow.

\subsection{Morphology of the micro-injected PLA/PA parts}

SEM micrographs of longitudinally cryofractured sections of micro-injection moulded parts of PLA/PA11-LV,PLA/PA11-HV, PLA-j/PA11-LV and PLA/PA6 blends are presented in Fig. 15 and 16.
The morphology of the microinjection moulded parts prepared from PLA/PA11-LV and PLA/PA11-HV blends are fibrillar despite the starting morphology in the extrudate is nodular. The diameter of fibrils of PA11 dispersed phase in the neat PLA matrix is between $0.2-0.8 \mu \mathrm{m}$ (averaged $0.47 \mu \mathrm{m}$ ) for PA11-LV grade and between 0.1-0.7 $\mu \mathrm{m}$ (averaged $0.31 \mu \mathrm{m}$ ) for PA11-HV grade. The fine fibrillar morphology for the PLA-j/ PA11-LV blend is conserved after microinjection moulding process. The diameter of PA11 dispersed phase is in the range of 0.1-0.5 $\mu \mathrm{m}$ (averaged $0.32 \mu \mathrm{m}$ ). The dispersed PA11 fibrils show tight contact with PLA-j matrix leaving no distinct voids between the elongated fibers and matrix. This indicates a good adhesion between the dispersed and continuous phases and these blends are extremely compatible. The average diameters of PA11 fibers for injection moulded PLA/PA11 and PLA-j/PA11 blends are summarized in Table 9.

In contrast to PLA/PA11 blends, the morphology is nodular for PLA/PA6 injection moulded specimens. The average diameter of dispersed phase domains in the presence of high viscoelastic polyamide 6 is $1.5 \mu \mathrm{m}$ with a large polydispersity FWHM of $1.1 \mu \mathrm{m}$. One can note that a part of the dispersed particles are pulled out from PLA matrix during the fracture, leaving holes on the observation surface indicating a low adhesion between PLA matrix and PA6 dispersed phase (Fig. 17).

The viscosity ratio $(k)$ between the viscosities of the dispersed phase to the matrix is calculated at a shear rate of $10^{5} \mathrm{~s}^{-1}$

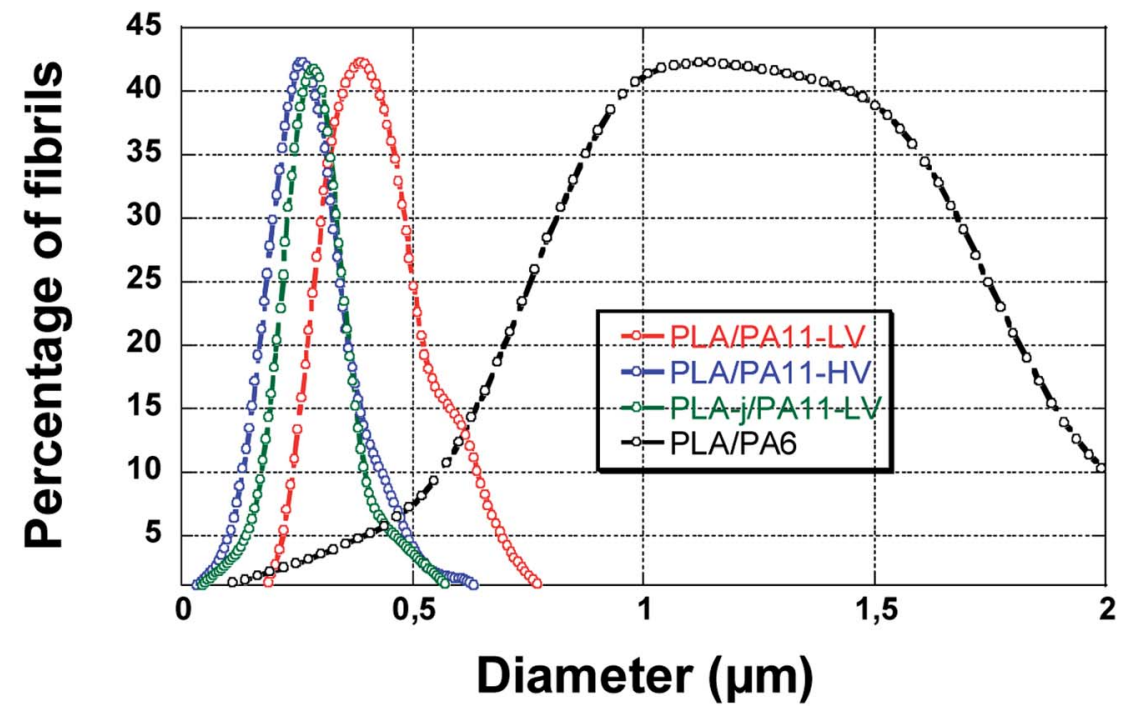

Fig. 17 The size distribution of PA dispersed phase in micro-injection-moulded parts for PLA/PA11 and PLA/PA6 blends. 
Table 10 Rheology data and swell die measurements from capillary rheometer for neat PLA, pure PLA-j, and PA11 at $200{ }^{\circ} \mathrm{C}$

\begin{tabular}{|c|c|c|c|c|}
\hline & Melt density $\left(\mathrm{g} \mathrm{cm}^{-3}\right)$ & $\eta_{\left(\text {at } 10000 \mathrm{~s}^{-1}\right)}(\mathrm{Pas})$ & $B$ (Swelling ratio) & $N_{1}(\mathrm{~Pa})$ \\
\hline PLA & 1.09 & 50 & 1.59 & $5.50 \times 10^{6}$ \\
\hline PLA $+1 \%$ Joncryl & 1.09 & 58.3 & 1.88 & $1.08 \times 10^{7}$ \\
\hline PA11 (PA11-HV) & 0.91 & 63.1 & 1.31 & $3.59 \times 10^{6}$ \\
\hline
\end{tabular}

Table 11 Rheology data and swell die measurements from capillary rheometer for neat PLA and neat PA6 at $230{ }^{\circ} \mathrm{C}$

\begin{tabular}{lllll}
\hline & Melt density $\left(\mathrm{g} \mathrm{cm}^{-3}\right)$ & $\eta_{\left(\text {at } 10000 \mathrm{~s}^{-1}\right)}(\mathrm{Pas})$ & $B($ Swelling ratio $)$ & $N_{1}(\mathrm{~Pa})$ \\
\hline PLA & 1.08 & 40 & 1.47 & $3.41 \times 10^{6}$ \\
PA6 & 0.98 & 136 & 1.55 & $1.38 \times 10^{7}$
\end{tabular}

corresponding nearly to the shear rate applied during the micro-injection moulding process $\left(\sim 8500 \mathrm{~s}^{-1}\right)$ previously measured by the digital image correlation technique (DIC).

Swell measurements are performed at $200^{\circ} \mathrm{C}$ and $230^{\circ} \mathrm{C}$ for PLA, at $200{ }^{\circ} \mathrm{C}$ for PA11 samples, and at $230{ }^{\circ} \mathrm{C}$ for PA6 samples. The $N_{1}$ values in these conditions are then calculated using eqn (24). The results are reported in the Tables 10-12.

At high shear rates $\left(10^{5} \mathrm{~s}^{-1}\right)$, favorable ratios for a stable fibrillation morphology are found for all PA11 based blends (PLA/PA11-LV, PLA/PA11-HV and PLA-j/PA11-LV). The viscosity ratios are closed to unity and the elasticity ratios are lower than 1 (Table 12); thus, the elasticity of the neat PLA is higher than PA11's ones at high shear rates. Therefore, the elasticity of the matrix (neat and modified PLA) is high enough to promote deformation and extension of the PA11 droplets, which is in agreement with SEM observations of microinjected specimens. As previously reported, at low shear rates $\left(80 \mathrm{~s}^{-1}\right)$, the morphology of PLA/PA11-LV and PLA/PA11-HV blends is nodular, but these same blends present suitable rheological properties to promote fibrillation of the dispersed phase at high shear rates.

In the case of blend prepared from PLA as matrix and PA6 as the dispersed phase, the viscosity ratios is higher than 3. PA6 exhibits also highest value of first normal stress difference, $N_{1}$. VanOene reported that the drop elasticity has a stabilizing effect, which restrains droplet from deformation and breaking. Therefore, the increase in elasticity ratio $\left(k^{\prime}>4\right)$ in the case of PLA/PA6 blends may prevent the droplet from the elongation to a stretched form under the shear/elongation flow field.

From these results, one can realize that there is a critical point (a critical shear rate) denoted $\dot{\gamma}_{\text {tr }}$ which corresponds to the intersection between $N_{1}(\dot{\gamma})$ curves of the matrix and that of the dispersed phase. The elasticity $N_{1}$ at low share rates is calculated from Laun eqn (15) and from eqn (21) for high share rates.

This critical shear rate $\dot{\gamma}$ trallows the transition from unsuitable to suitable rheological conditions to develop nanofibrils from PA droplets.

It can be noted that the critical shear rate for PLA/PA11-LV blendsis found to be about $520 \mathrm{~s}^{-1}$ and for PLA/PA11-HV blend is about $3700 \mathrm{~s}^{-1}$. From these critical shear rates, the elasticity of the blend components becomes suitable to promote fibrillation. These results are in agreement with observed SEM images of the blends when high shear rate $\left(>8500 \mathrm{~s}^{-1}\right)$ is applied during micro-injection moulding. Since the elasticity ratio of PLA-j/PA11-HV is lower than that of PLA/PA11-HV, the critical shear rate decreases from $3700 \mathrm{~s}^{-1}$ to $1000 \mathrm{~s}^{-1}$ respectively. This shows that the more the elasticity ratio decreases the more the in situ fibrillation becomes favorable in the micro-injection moulding. In the case of PLA/PA6 blends, no critical shear rate is observed indicating a predominant nodular morphology regardless of the applied shear rate range investigated from $10^{-1}$ to $10^{5} \mathrm{~s}^{-1}$.

From the critical shear rates obtained, one can predict the average radius of particles corresponding to the droplet/fibril transition (Fig. 18).

As reported above, the transition from droplets to stable filaments is achieved when $\mathrm{Ca}=4 \mathrm{Ca}_{\text {(crit) }}$ where $\mathrm{Ca}$ and $\mathrm{Ca}_{\text {(crit) }}$ are the capillary number and critical capillary number respectively.

The $\mathrm{Ca}_{\text {(crit) }}$ number at the critical shear rate corresponding to droplet-fibril transition is $\mathrm{Ca}_{\text {(crit) }}=\eta_{\mathrm{m}} \dot{\gamma}_{\mathrm{tr}} /\left(\Gamma_{\mathrm{d}, \mathrm{m}} / R_{\text {fibril }}\right)$ where $\eta_{\mathrm{m}}$ is the matrix viscosity at the critical shear rate, $\Gamma_{\mathrm{d}, \mathrm{m}}$ is the interfacial tension and $R_{\text {fibril }}$ is the radius of the fibril at the droplet-fibril transition.

Using the $\mathrm{Wu}$ eqn (4) to determine the critical capillary number $\mathrm{Ca}_{\text {(crit) }}$ (Section 1), this gives the following relation:

$$
R_{\text {fibril }}=\frac{16 \Gamma_{\mathrm{d}, \mathrm{m}}\left(\frac{\eta_{\mathrm{d}}}{\eta_{\mathrm{m}}}\right)^{ \pm 0.84}}{\dot{\gamma}_{\mathrm{tr}} \eta_{m}}
$$

Table 12 Viscosity and elasticity ratios for PLA/PA11 and PLA/PA6 blends at $10000 \mathrm{~s}^{-1}$

\begin{tabular}{llll}
\hline Blends system & $\begin{array}{l}k \\
\text { (viscosity ratio) }\end{array}$ & $\begin{array}{l}k^{\prime} \\
\text { (elasticity ratio) }\end{array}$ & $\begin{array}{l}\text { Type of } \\
\text { morphology }\end{array}$ \\
\hline PLA/PA11-LV & 1.4 & 0.55 & Fibrillar \\
PLA/PA11-HV & 1.2 & 0.65 & Fibrillar \\
PLA/PA6 & 3.4 & 4.1 & Nodular \\
PLA-j/PA11-LV & 1.2 & 0.28 & Fibrillar
\end{tabular}



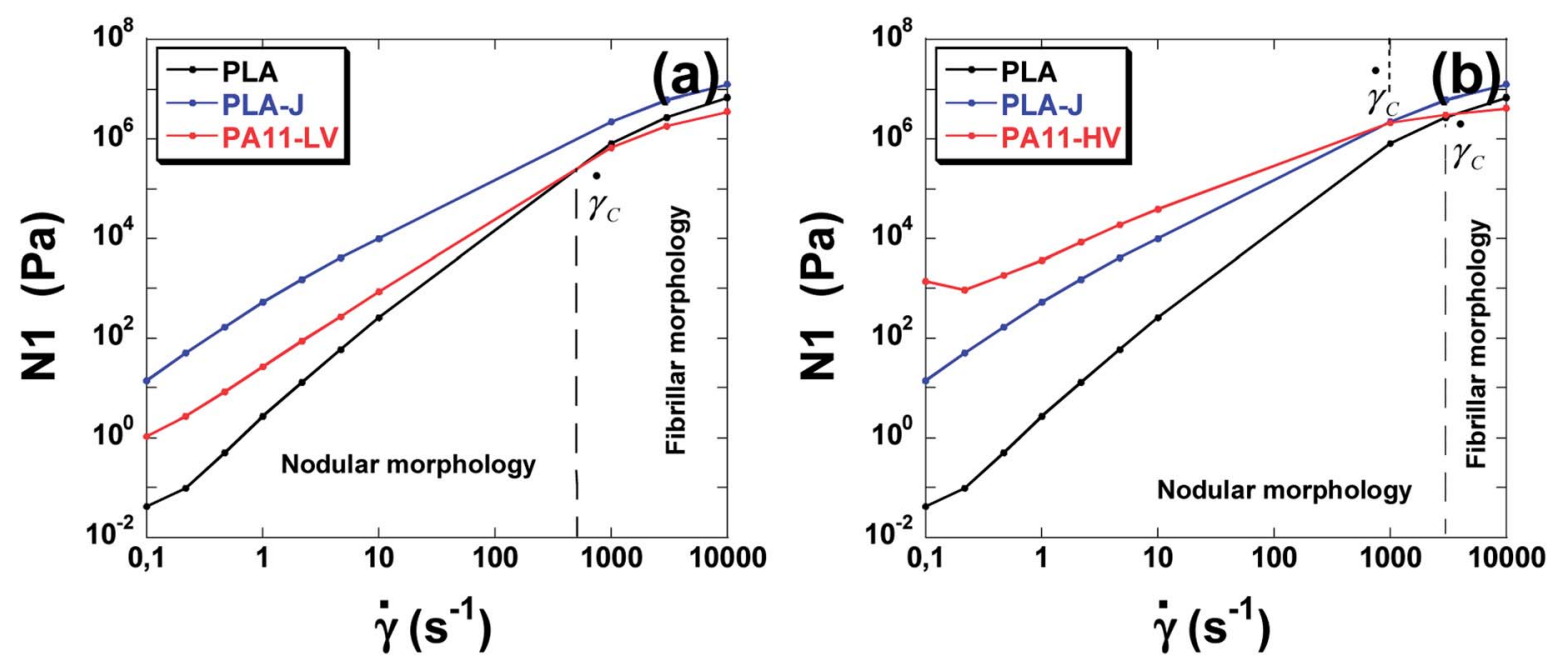

Fig. 18 The elasticity of neat polymers used as a function of shear rate. (a) PLA, PLA-j and PA11-LV, (b), PLA, PLA-j and PA11-HV.

Table 13 Reduced breakup time and characteristic time for flow induced deformation of different PLA/PA blends in the injection moulding parts

\begin{tabular}{lll}
\hline Blend system & Reduced breakup time $t_{\mathrm{b}}^{*}$ & $(\dot{\gamma})^{-1}$ \\
\hline PLA/PA11-LV & 0.49 & 0.00012 \\
PLA/PA11-HV & 0.37 & \\
PLA/PA6 & 0.64 & \\
PLA-j/PA11-LV & 0.40 & \\
\hline
\end{tabular}

The calculation gives $R_{\text {fibril }}$ equals to $0.22 \mu \mathrm{m}$ for PLA/PA11-LV blends and $0.125 \mu \mathrm{m}$ for PLA/PA11-HV blends. These results are in perfect consistence with the above SEM image analyzes who gave average fibers radius of $0.25 \mu \mathrm{m}$ and $0.15 \mu \mathrm{m}$ for PLA/PA11LV and PLA/PA11-HV respectively.

Finally, the reduced breakup time is calculated for different PLA/PA blends in the injection-moulding parts and compared to the characteristic time for flow induced deformation (the inverse of the shear rate)in the shear zone of the feed channel of the injection moulding machine $\left(\dot{\gamma}^{-1}\right)$. The results are summarized in Table 13. In all cases, the break-up time is much higher than the residence time indicating the stability of the obtained fibrillar morphologies.

\subsection{Mechanical properties of PLA/PA blends}

The tensile properties of PLA/PA blends are given in Table 14 . Fig. 19 compares the mechanical performance of the microinjection moulded specimens prepared from neat polymers and PLA-PA11 blends. It is well known that PLA has a high tensile strength and modulus but is brittle. It can be seen that PA11 has obviously moderate yield stress and tensile modulus but a higher elongation at break. Furthermore, blending PA11 with PLA improves the mechanical performance of the PLA matrix. The tensile stress-strain behaviour changes from brittle (for the neat PLA) to ductile (for the PLA/PA11) blend as demonstrated by the increase in the elongation at break from $8.9 \%$ for neat PLA to $94.8 \%$ and $268.9 \%$ for PLA/PA11-LV and PLA/PA11-HV respectively, without sacrificing the stiffness. Compared to neat PLA matrix, the tensile modulus decreases by $11 \%$ and $18 \%$ in the case of PLA/PA11-LV and PLA/PA11-HV respectively. The obvious enhancement in mechanical performance of PLA could be explained by the highly oriented structures formed by the PA11 fibrils which are previously reported by SEM observations.

The ratio of the viscoelastic properties of the phases certainly influences the type of morphology, the form of the particles of the disperse phase (droplets or fibrils) and their size. However, in this study, the link between the morphology and mechanical

Table 14 Tensile strength, elongation at break and tensile modulus of neat polymers and PLA/PA blends

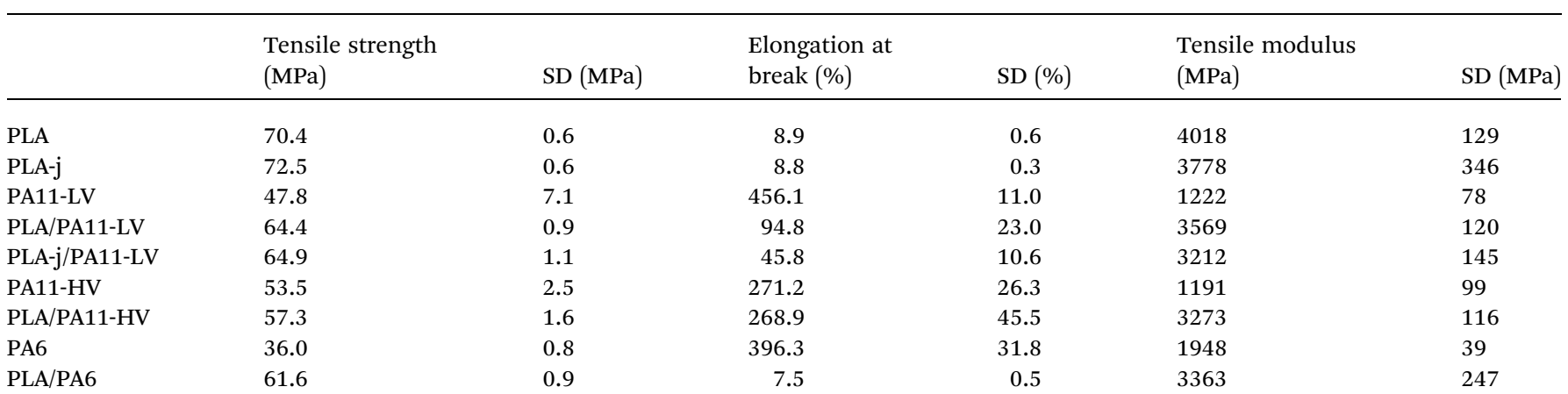




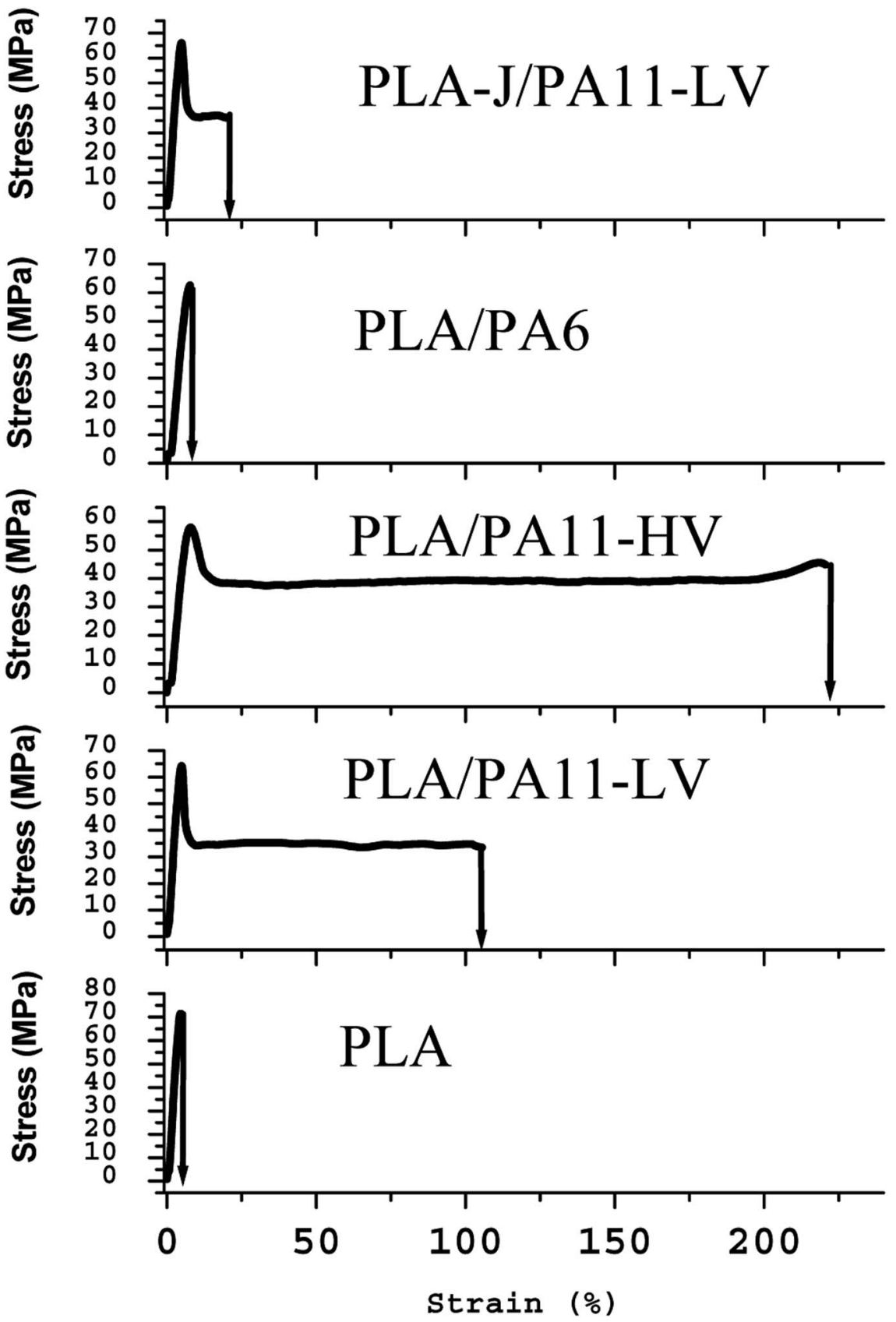

Fig. 19 Tensile stress versus tensile strain of neat PLA and various polymer blends.

properties is not reflected for all blend samples. Although PLA-j/ PA11-LV microinjection moulded specimens adopt predominant nanofibrillar morphology with well oriented nanofibrils; nevertheless, they have an elongation at break two times lower than that of PLA/PA11-LVfibrillar blends while the tensile strength and Young's modulus remain similar. This is probably due to the high percentage of branching groups used (1\% by weight) of $\ll \mathrm{CE} \gg$. Indeed, similar results were reported recently by Ma et al. ${ }^{85}$ when using dicumyl peroxide (DCP) as a chain extender for PLA matrix. They found that the ductility of PLA/PBAT blends decreases with the increasing in chainextender content. At $0.1 \mathrm{wt} \%$ by weight of DCP, the elongation at break was $300 \%$, and it goes down to $40 \%$ with 1 wt $\%$ DCP. But the authors give no explanation for this phenomenon.

In the case of PLA/PA6 blends having a nodular morphology, a coarsening of the microstructure is observed which leads to a loss in ductility which would be associated with the relative decrease in the amount of interface, occurring together with the increase of the polydispersity and the domain size of the PA6 phases as previously observed from SEM micrographs. The tensile modulus of PLA/PA6 blend decreases by $16 \%$ compared to neat PLA matrix.

It is useful to mention that it is reported in different literature reports ${ }^{86,87}$ that in comparison with conventional injection moulding processes, the combination of higher shear rates and 
faster cooling rates in the micro-injection moulding process (mainly due to reduced thickness) favor the formation of highly oriented fibrils in the microparts compared to conventional macroparts. Accordingly, the fraction of the oriented structures formed during micro-injection moulding is higher than those formed during conventional injection moulding. This study is under investigation in our laboratory.

\section{Conclusion}

SEM analysis of PLA/PA blends showed that in the immiscible PLA/PA extrudates, the phase structure without the chain extender agent was predominantly nodular and totally fibrillar for the blend prepared with $1 \% \mathrm{CE}$ agent, against a totally fibrillar morphology for microinjected moulded parts. The results showed also that the incorporation of the chain extension agent improved the adhesion between PLA and PA11 inducing the formation on in situ nano(fibrillated) polymer/ polymer composites. In addition to the viscosity ratio, the effect of the elasticity ratio on the blend morphology was highlighted. Although the elasticity ratio was not favorable to fibrillation during the extrusion step, the situation could be reversed during the high shear rate injection moulding process. Critical shear rates and fibrils sizes related to the transition from nodular to fibrillar morphology have been determined and the results are in good agreement with the condition of fibrillation $\mathrm{Ca} / \mathrm{Ca}$ (crit) $_{2} \geq 4$. Regarding the mechanical performances, a drastic increase of the ductility was observed in the PLA/PA11 blends compared with pure PLA (with an elongation at break greater than $90 \%$ against only $9 \%$ for neat PLA), without sacrificing meanwhile the stiffness.

\section{Conflicts of interest}

There are no conflits to declare.

\section{Acknowledgements}

The authors are indebted for valuable assistance provided by Dr. Salim Chaki from IMT-Lille Douai in Digital Image Correlation experiments. They acknowledge Ms. Justine Piquet from IMT-Lille Douai for surface energy measurements. The authors also gratefully acknowledge the International Campus on Safety and Intermodality in Transportation (CISIT), the Nord-Pas-deCalais Region and the European Community (FEDER funds) for funding contribution to the acquisition of the microinjection moulding machine, the dynamic rheometer and the scanning electron microscope.

\section{References}

1 C. W. Macosko, Macromol. Symp., 2000, 149, 171-184.

2 H. E. H. Meijer, P. J. Lemstra and P. H. M. Elemans, Makromolekulare Chemie-Macromolecular Symposia, 1988, 16, 113-135.
3 G. I. Taylor, Proceedings of the Royal Society of London. Series A, Containing Papers of a Mathematical and Physical Character, 1932, vol. 138, pp. 41-48.

4 H. P. Grace, Chem. Eng. Commun., 1982, 14, 225-277.

5 F. Rumscheidt and S. Mason, J. of Colloid Sci., 1961, 16, $238-$ 261.

6 H. Karam and J. Bellinger, Ind. Eng. Chem. Res., 1968, 7, 576581.

7 S. Torza, R. Cox and S. Mason, J. Colloid Interface Sci., 1972, 38, 395-411.

8 L. Levitt, C. W. Macosko and S. D. Pearson, Polym. Eng. Sci., 1996, 36, 1647-1655.

9 S. Tomotika, Proc. R. Soc. A, 1935, 150, 322-337.

10 L. Rayleigh, P. Lond. Math. Soc., 1878, 10, 4-13.

11 S. Tomotika, Proc. R. Soc. A, 1936, 153, 302-318.

12 Y. Seo and J. Kim, Polymer, 2001, 42, 5029-5036.

13 P. Cassagnau and A. Michel, Polymer, 2001, 42, 3139-3152.

14 I. Pesneau, A. A. Kadi, M. Bousmina, P. H. Cassagnau and A. Michel, Polym. Eng. Sci., 2002, 42, 1990-2004.

15 S. H. Wu, Polym. Eng. Sci., 1987, 27, 335-343.

16 G. Serpe, J. Jarrin and F. Dawans, Polym. Eng. Sci., 1990, 30, 553-565.

17 W. Lerdwijitjarud, A. Sirivat and R. G. Larson, Polym. Eng. Sci., 2002, 42, 798-809.

18 S. Wu, Polym. Eng. Sci., 1987, 27, 335-343.

19 Y. Deyrail, R. Fulchiron and P. Cassagnau, Polymer, 2002, 43, 3311-3321.

20 Y. Deyrail, A. Michel and P. Cassagnau, Can. J. Chem. Eng., 2002, 80, 1017-1027.

21 M. A. Huneault, M. F. Champagne and A. Luciani, Polym. Eng. Sci., 1996, 36, 1694-1706.

22 A. Luciani and J. Jarrin, Polym. Eng. Sci., 1996, 36, 1619-1626.

23 W. Berger, H. W. Kammer and C. Kummerlőwe, Die Makromolekulare Chemie, 1984, 10, 101-108.

24 P. H. M. Elemans, Modelling of the processing of incompatible polymer blends, Eindhoven University, 1989.

25 V. E. Dreval, G. V. Vinogradov, E. P. Plotnikova, M. P. Zabugina, N. P. Krasnikova, E. V. Kotova and Z. Pelzbauer, Rheol. Acta, 1983, 22, 102-107.

26 A. Taguet, P. Cassagnau and J. M. Lopez-Cuesta, Prog. Polym. Sci., 2014, 39, 1526-1563.

27 U. Sundararaj and C. W. Macosko, Macromolecules, 1995, 28, 2647-2657.

28 R. A. De Bruijn, Deformation and breakup of drops in simple shear flows, Eindhoven university, 1989.

29 J. J. Elmendorp, A study of polymer blending microrheology, Delft University of Technology, 1986.

30 M. V. Tsebrenko, N. M. Rezanova and I. A. Tsebrenko, Polym. Eng. Sci., 1999, 39, 2395-2402.

31 C. L. Tucker and P. Moldenaers, Annu. Rev. Fluid Mech., 2002, 34, 177-210.

32 J. J. Elmendorp and R. J. Maalcke, Polym. Eng. Sci., 1985, 25, 1041-1047.

33 F. Gauthier, H. L. Goldsmith and S. G. Mason, Rheol. Acta, 1971, 10, 344-364.

34 P. P. Varanasi, M. E. Ryan and P. Stroeve, Ind. Eng. Chem. Res., 1994, 33, 1858-1866. 
35 W. J. Milliken and L. G. Leal, J. Non-Newtonian Fluid Mech., 1991, 40, 355-379.

36 S. Guido and M. Villone, J. Rheol., 1998, 42, 395-415.

37 F. Abbassi-Sourki, M. A. Huneault and M. Bousmina, Polymer, 2009, 50, 645-653.

38 T. Cherdhirankorn, W. Lerdwijitjarud, A. Sirivat and R. G. Larson, Rheol. Acta, 2004, 43, 246-256.

39 W. Lerdwijitjarud, R. G. Larson, A. Sirivat and M. J. Solomon, J. Rheol., 2003, 47, 37-58.

40 Y. W. Stegeman, F. N. van de Vosse and H. E. H. Meijer, Can. J. Chem. Eng., 2002, 80, 632-637.

41 N. A. Plate, V. G. Kulichikhin and R. V. Talroze, Pure Appl. Chem., 1991, 63, 925-940.

42 H. Vanoene, J. Colloid Interface Sci., 1972, 40, 448-467.

43 J. Reignier, B. D. Favis and M. C. Heuzey, Polymer, 2003, 44, 49-59.

44 H. A. Stone, B. J. Bentley and L. G. Leal, J. Fluid Mech., 1986, 173, 131-158.

45 L. Rayleigh, 1879.

46 M. Huneault, M. Champagne and A. Luciani, Polym. Eng. Sci., 1996, 36, 1694-1706.

47 C. D. Han, Multiphase Flow in Polymer Processing, New York, 1981.

48 A. Acrivos, Ann. N. Y. Acad. Sci., 1983, 404, 1-11.

49 J. M. Rallison, Annu. Rev. Fluid Mech., 1984, 16, 45-66.

50 L. A. Utracki and Z. H. Shi, Polym. Eng. Sci., 1992, 32, 18241833.

51 P. H. M. Elemans, H. L. Bos, J. M. H. Janssen and H. E. H. Meijer, Chem. Eng. Sci., 1993, 48, 267-276.

52 K. Friedrich, J. Hoffmann, M. Evstatiev and S. Fakirov, in Recent Advances in Composite Materials, ed. S. a. Paipetis, 2003, pp. 203-214.

53 B. J. Rashmi, K. Prashantha, M. F. Lacrampe and P. Krawczak, Exp. Polym. Lett., 2015, 9, 721-735.

54 G. Stoclet, R. Seguela and J. M. Lefebvre, Polymer, 2011, 52, 1417-1425.

55 Q. K. Meng, M. C. Heuzey and P. J. Carreau, Polym. Degrad. Stab., 2012, 97, 2010-2020.

56 M. Yousfi, S. Alix, M. Lebeau, J. Soulestin, M.-F. Lacrampe and P. Krawczak, Polym. Test., 2014, 40, 207-217.

57 D. K. Owens and R. C. Wendt, J. Appl. Polym. Sci., 1969, 13, 1741-1747.

58 S. Wu, Polymer Interface and Adhesion, Dekker, New York, 1982.

59 V. Khoshkava and M. R. Kamal, Biomacromolecules, 2013, 14, 3155-3163.

60 I. McDougall, N. Orbey and J. M. Dealy, J. Rheol., 2014, 58, 779-797.

61 J. Honerkamp and J. Weese, Macromolecules, 1989, 22, 43724377.
62 H. M. Laun, J. Rheol., 1986, 30, 459-501.

63 M. Astruc, S. Vervoort, H. O. Nouatin, T. Coupez, Y. De Puydt, P. Navard and E. Peuvrel-Disdier, Rheol. Acta, 2003, 42, 421431.

64 Y. Iso, C. Cohen and D. L. Koch, J. Non-Newtonian Fluid Mech., 1996, 62, 135-153.

65 M. Xanthos, V. Tan and A. Ponnusamy, Polym. Eng. Sci., 1997, 37, 1102-1112.

66 R. I. Tanner, J. Non-Newtonian Fluid Mech., 2005, 129, 85-87.

67 E. A. Jensen and J. D. Christiansen, J. Non-Newtonian Fluid Mech., 2008, 148, 41-46.

68 M. Tagawa, K. Gotoh, A. Yasukawa and M. Ikuta, Colloid Polym. Sci., 1990, 268, 589-594.

69 A. Cayla, C. Campagne, M. Rochery and E. Devaux, Synth. Met., 2011, 161, 1034-1042.

70 R. Al-Itry, K. Lamnawar and A. Maazouz, Polym. Degrad. Stab., 2012, 97, 1898-1914.

71 R. Al-Itry, K. Lamnawar and A. Maazouz, Eur. Polym. J., 2014, 58, 90-102.

72 R. Salehiyan, T. Malwela and S. S. Ray, Polym. Degrad. Stab., 2017, 139, 130-137.

73 D. J. Dijkstra, Pure Appl. Chem., 2009, 81, 339-349.

74 D. F. Wu, L. J. Yuan, E. Laredo, M. Zhang and W. D. Zhou, Ind. Eng. Chem. Res., 2012, 51, 2290-2298.

75 N. Najafi, M. C. Heuzey, P. J. Carreau, D. Therriault and C. B. Park, Rheol. Acta, 2014, 53, 779-790.

76 Y. Zhou, F. Yu, H. Deng, Y. Huang, G. Li and Q. Fu, J. Phys. Chem. B, 2017, 121, 6257-6270.

77 F. Walha, K. Lamnawar, A. Maazouz and M. Jaziri, Polymers, 2016, 8, 61.

78 R. E. Riemann, H. J. Cantow and C. Friedrich, Polym. Bull., 1996, 36, 637-643.

79 A. Y. Malkin, J. Non-Newtonian Fluid Mech., 2013, 192, 48-65.

80 M. V. Tsebrenko, A. V. Yudin, T. I. Ablazova and G. V. Vinogradov, Polymer, 1976, 17, 831-834.

81 M. V. Tsebrenko, G. P. Danilova and A. Y. Malkin, J. NonNewtonian Fluid Mech., 1989, 31, 1-26.

82 F. Mighri, A. Ajji and P. J. Carreau, J. Rheol., 1997, 41, 11831201.

83 F. Mighri, P. J. Carreau and A. Ajji, J. Rheol., 1998, 42, 14771490.

84 F. Fenouillot and H. Perier-Camby, Polym. Eng. Sci., 2004, 44, 625-637.

85 P. Ma, X. Cai, Y. Zhang, S. Wang, W. Dong, M. Chen and P. J. Lemstra, Polym. Degrad. Stab., 2014, 102, 145-151.

86 Z. M. Li, B. H. Xie, S. Y. Yang, R. Huang and M. B. Yang, J. Mater. Sci., 2004, 39, 433-443.

87 P. Deng, K. J. Liu, L. Zhang, H. Liu, T. Wang and J. Zhang, J. Macromol. Sci., Part B: Phys., 2014, 53, 24-39. 